\title{
The application of SEAT values for predicting how compliant seats with backrests influence vibration discomfort
}

Authors:

Bazil Basri and Michael J. Griffin

Affiliations:

Human Factors Research Unit

Institute of Sound and Vibration Research

University of Southampton

Southampton, SO17 1BJ

England

Corresponding author:

Professor Michael J. Griffin

Tel: +44 (0) 2380592277

Fax: +44 (0) 2380592927

Email: M.J.Griffin@soton.ac.uk 


\section{ABSTRACT}

The extent to which a seat can provide useful attenuation of vehicle vibration depends on three factors: the characteristics of the vehicle motion, the vibration transmissibility of the seat, and the sensitivity of the body to vibration. The 'seat effective amplitude transmissibility' (i.e., SEAT value) reflects how these three factors vary with the frequency and the direction of vibration so as to predict the vibration isolation efficiency of a seat. The SEAT value is mostly used to select seat cushions or seat suspensions based on the transmission of vertical vibration to the principal supporting surface of a seat. This study investigated the accuracy of SEAT values in predicting how seats with backrests influence the discomfort caused by multiple-input vibration. Twelve male subjects participated in a four-part experiment to determine equivalent comfort contours, the relative discomfort, the location of discomfort, and seat transmissibility with three foam seats and a rigid reference seat at 14 frequencies of vibration in the range 1 to $20 \mathrm{~Hz}$ at magnitudes of vibration from 0.2 to $1.6 \mathrm{~ms}^{-2}$ r.m.s. The 'measured seat dynamic discomfort' (MSDD) was calculated for each foam seat from the ratio of the vibration acceleration required to cause similar discomfort with the foam seat and with the rigid reference seat. Using the frequency weightings in current standards, the SEAT values of each seat were calculated from the ratio of overall ride values with the foam seat to the overall ride values with the rigid reference seat, and compared to the corresponding MSDD at each frequency. The SEAT values provided good predictions of how the foam seats increased vibration discomfort at frequencies around the $4-\mathrm{Hz}$ resonance but reduced vibration discomfort at frequencies greater than about $6.3 \mathrm{~Hz}$, with discrepancies explained by a known limitation of the frequency weightings.

Keywords: objective measurement; prediction model; seating comfort, seat design, backrest inclination 


\section{INTRODUCTION}

To reduce the discomfort arising from vibration, vehicle seats can be designed to minimise the transmission of vibration. The optimisation of the vibration transmissibility of a seat requires understanding of how vibration discomfort can be predicted from the vibration experienced at the seat surfaces.

The dynamic properties of a seat (e.g., damping and stiffness) are influenced by the physical properties of foam or other material (e.g., density, thickness, firmness) that might be engineered to achieve the desired seating comfort including vibration isolation. The most common method of quantifying the dynamic properties of a seat is the seat transmissibility. This shows how the ratio of vibration measured at the subject-seat interface to the vibration in the same direction on the floor varies according to the frequency of the vibration. The vertical transmissibility from the floor beneath the seat to the surface on the seat squab beneath the ischial tuberosities of a person is most often measured, but non-vertical transmissibility, and the transmissibility to other locations, especially the backrest, are also studied. Unless a seat is entirely rigid, the transmissibility invariably shows that vibration is amplified at some frequencies (i.e., at the resonance frequency) and attenuated at other frequencies. There may be a vertical resonance of a seat squab around $4 \mathrm{~Hz}$ (e.g., Corbridge et al., 1989) and fore-and-aft resonance through a seat backrest around $5 \mathrm{~Hz}$ (Qiu and Griffin, 2003). However, the transmissibility of a seat is not sufficient to predict vibration discomfort. Discomfort can arise from multiple-input vibration (at a seat squab, at a backrest, and at the feet) and the motion can be complex (e.g., multiple-axis and multiple-frequency or random). The contribution of each input to vibration discomfort must be understood if the transmissibility of a seat is to be optimised (Griffin, 2007).

The optimisation of the vibration transmissibility of a seat should not be confined to minimising the amplification that occurs at the resonance frequency. The optimisation must include consideration of all frequencies of vibration that occur on the floor supporting the seat, the extent to which these are transmitted through the seat, and the extent to which they influence comfort, or some other human response (e.g., interference with activities or health). The Seat Effective Amplitude Transmissibility (i.e., SEAT value) was introduced to combine these three functions of frequency in a single value indicating the extent to which a seat improves or degrades vibration discomfort (Griffin, 1978, 1990). The SEAT value may be considered the ratio of the vibration discomfort experienced when sitting on a seat to the vibration discomfort that would be experienced when sitting on a rigid seat (or sitting on the floor). A value greater than $100 \%$ (or 1.0) indicates how much the vibration discomfort is increased by the seat. Ideally, seats have SEAT values less than $100 \%$, but this is not always the case. The calculation of a SEAT value requires understanding of how vibration 
discomfort depends on the frequency of vibration. Originally, this was achieved using the frequency-dependence of the reduced-comfort boundary in the first version of ISO 2631 (1974), but the frequency weightings in later standards are now used (i.e., BS 6841:1987, ISO 2631-1:1997). The SEAT concept has been adopted in various standards for quantifying the efficiency of seats in isolating vertical vibration (e.g., ISO 10326-1:1992, ISO 7096:2000).

Although the SEAT value is most usually applied to quantify the vertical isolation efficiency of the seat squab (or seat suspension), it can be used for other directions of vibration. For example, it can be used to quantify the efficiency of a seat in isolating the transmission of fore-and-aft vibration to the backrest (Griffin, 1990). More generally, a SEAT value can be used to quantify the overall isolation efficiency of seat by a single value, taking into account multi-axis vibration transmitted to both the seat squab and the backrest.

The concept behind the SEAT value is intuitively obvious: it uses a method of predicting vibration discomfort to compare the vibration discomfort when sitting in a seat to the vibration discomfort that will be experienced when sitting in a reference seat (i.e., a rigid seat). Nevertheless, there are assumptions that are not entirely obvious. For example, the method will not provide a good estimate of the isolation efficiency of a seat if the weightings for the frequency of vibration or the direction of vibration do not accurately reflect how vibration discomfort varies with the frequency or direction of vibration. There will also be errors if the method of combining the vibration experienced in different directions, or at different locations, or in different postures (e.g., due to inclined backrests) is not appropriate. Although the SEAT value is widely used, there has been little investigation of how well it predicts the influence of realistic seats on vibration discomfort.

With solely vertical vibration (often the dominant direction in transport), the vibration isolation efficiency of a seat can be predicted from a SEAT value calculated from vertical vibration at the seat pan (using frequency weighting $W_{\mathrm{b}}$ from BS 6841:1987 or frequency weighting $W_{\mathrm{k}}$ from ISO 2631-1:1997) and vibration at the backrest (using frequency weightings $W_{\mathrm{c}}$ and $\left.W_{d}\right)(G r i f f i n, 2007)$. However, seats usually have inclined backrests and it has been reported that the $W_{\mathrm{c}}$ weighting overestimates the discomfort caused by $x$-axis vibration of inclined backrests at low frequencies and underestimates at frequencies greater than $8 \mathrm{~Hz}$ (Kato and Hanai, 1998; Basri and Griffin, 2011). Furthermore, with increasing inclination of a backrest there is greater support for the upper-body and the relative importance of vertical seat pan vibration is reduced (Basri and Griffin, 2012; 2013). It is not known how well a SEAT value based on currently standardised weightings will predict the overall vibration discomfort when sitting in a compliant seat with an inclined backrest. 
The experiment reported here was designed to investigate how the compliance of seats with inclined backrests influence vibration discomfort. The effect of seat compliance on SEAT values (calculated from evaluations of vibration at the seat, the back, and the feet) was compared with the effect of seat compliance on judgements of vibration discomfort.

\section{METHOD}

\section{$2.1 \quad$ Apparatus}

A rigid seat frame was constructed from aluminium extrusions with a flat horizontal wooden seat pan $(500 \times 440 \mathrm{~mm})$, flat wooden backrest $(400 \times 630 \mathrm{~mm})$ inclined $30^{\circ}$ from the vertical, and a flat wooden footrest $(500 \times 340 \mathrm{~mm})$ inclined $60^{\circ}$ from the vertical (Figure 1). The dimensions of the seat were designed to provide a comfortable sitting posture for a $50^{\text {th }}$ percentile British male aged 19 to 45 years (Pheasant, 1990). The surface of the rigid seat pan and backrest were covered with 1-mm thick neoprene rubber to provide friction. There was no headrest.

\section{FIGURE 1 ABOUT HERE}

Four seating conditions were tested: three compliant seats and the rigid seat. The compliant seats consisted of two rectangular polyurethane blocks placed on the horizontal surface of the rigid seat and secured to the inclined backrest. Three different blocks of foam on the seat

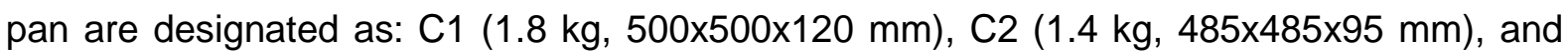
C3 $(1.2 \mathrm{~kg}, 455 \times 405 \times 105 \mathrm{~mm})$. The block of foam secured to the backrest is designated as B1 $(1.0 \mathrm{~kg}, 380 \times 610 \times 70 \mathrm{~mm})$. The foams for the seat pan were chosen primarily for their differences in apparent stiffness: C3 was the hardest and C1 was slightly softer than C2. The surface of the rigid seat pan and backrest were covered with 1-mm thick neoprene rubber to provide friction with the body. There was no headrest.

A rigid footrest was used in all conditions. The height of the footrest was adjusted to provide similar thigh contact in all condition (with the upper surface of the upper legs approximately horizontal). A loose lap belt was provided for safety but did not restrain subjects during vibration.

The seat was securely mounted to the platform of a hydraulic vibrator capable of 1-meter peak-to-peak displacement in the vertical direction. 


\subsection{Signal generation and acquisition}

The acceleration of the vibrator platform was monitored using single-axis piezo-resistive accelerometers (Entran Model EGCSY-240D-10) attached on the platform. The acceleration of the inclined backrest was measured in the $x$-axis and the $z$-axis of the subject (i.e., at 30 degrees to the horizontal and 30 degrees to the vertical, respectively), using similar accelerometers. The accelerations at the interfaces between the body and the foam were monitored using two tri-axial SIT-pads conforming to ISO 10326-1 (1992). The SIT-pad at the seat pan was positioned $180 \mathrm{~mm}$ forward from the centre to the rear edge of foam on the seat pan so subjects could sit with the SIT-pad beneath their ischial tuberosities. The SITpad at the backrest was nominally positioned $550 \mathrm{~mm}$ from the centre to the top edge of the backrest foam. The position of this SIT-pad was adjusted according to the height of subjects so that it was in contact with the upper back (around the upper thoracic region between $\mathrm{C} 7$ and T3).

Vibration stimuli were generated and sampled using HVLab Signal Processing Toolbox in Matlab (version R2010) and output via a digital-to-analogue converter ( $\mathrm{NI} \mathrm{6211)} \mathrm{at} 512$ samples per second. Signals from the accelerometers were low-pass filtered at $50 \mathrm{~Hz}$ and then sampled at 512 samples per second.

\subsection{Procedure}

The experiment was conducted in four sessions corresponding to four seating conditions (i.e., the rigid seat and the three compliant seats, C1, C2, and C3). Each subject completed all four sessions within two days, with two sessions per day. Each session lasted less than 40 minutes. The order of sessions was balanced across subjects.

Each session comprised three psychophysical tests and one objective test:

Part 1: Equivalent comfort contours within seating condition,

Part 2: Relative discomfort between seating conditions,

Part 3: Location of discomfort, and

Part 4: Seat transmissibility.

Subjects used the method of magnitude estimation to judge the discomfort produced by test stimuli relative to the discomfort produced by a reference stimulus. The sinusoidal vibrations were of 5-s duration (including 1-s cosine-tapering at the start and the end). To confirm understanding of the magnitude estimation method, subjects initially judged the apparent length of several lines relative to the apparent length of a reference line. They then practiced judging the discomfort caused by vibrations before commencing the experiment on their first 
day. Subjects were able to ask for stimuli to be repeated if they were unsure of their judgement.

Subjects were required to close their eyes during the presentation of the stimuli they were judging so as to avoid seeing the motion of the vibrator and their motion relative to the laboratory. They wore headphones presenting a masking white noise at $65 \mathrm{~dB}(\mathrm{~A})$. The experimenter and the subjects were provided with separate emergency stop buttons.

\subsubsection{Equivalent comfort contours within seating condition: Part 1}

In Part 1 of the study, subjects sat in each of the four seating conditions and used the method of magnitude estimation to judge the discomfort produced by 56 test stimuli from an array of 14 frequencies (from 1 to $20 \mathrm{~Hz}$ in one-third octave intervals) at four vibration magnitudes (0.2, $0.4,0.8$ and $1.6 \mathrm{~ms}^{-2}$ r.m.s.).

In this part of the study, subjects sat on the seat pan with backrest contact (i.e., back leaning comfortably against the backrest) with their hands resting on their laps. There was no support for the head: to control the posture of the head, subjects were requested to look straight ahead as when driving.

Subjects were presented with a reference stimulus followed by a test stimulus and asked to estimate the magnitude of vibration discomfort, $\psi$, produced by the test stimulus (of acceleration magnitude, $\varphi$ ) assuming the reference stimulus (8 $\mathrm{Hz}$ at $0.4 \mathrm{~ms}^{-2}$ r.m.s.) produced a vibration discomfort of 100 . The 56 pairs of test-reference stimuli, separated by 2-second pauses, were presented in a different randomised order to each subject. This part of the study took approximately 15 minutes.

\subsubsection{Relative discomfort between seating conditions: Part 2}

In Part 2 of the study, within each of the four seating conditions, subjects judged the vibration discomfort caused by four levels of $8-\mathrm{Hz}$ test stimuli $\left(0.2,0.4,0.8\right.$ and $1.6 \mathrm{~ms}^{-2}$ r.m.s.) when sitting against the backrest relative to their vibration discomfort when sitting without backrest contact. There were two conditions: (i) subjects sat upright without backrest contact during the presentation of reference and test stimuli, and (ii) subjects sat upright without backrest contact during the presentation of the reference stimulus and then leant back so that they were sitting with backrest contact (as in Part 1) during the presentation test stimuli. The stimuli were presented when subjects had adjusted to the required posture and were ready.

In both conditions, subjects estimated the magnitude of their vibration discomfort, $\psi$, produced by each test stimulus (of acceleration magnitude, $\varphi$ ) assuming the reference 
stimulus (8 $\mathrm{Hz}$ at $0.4 \mathrm{~ms}^{-2}$ r.m.s.) produced a vibration discomfort of 100 . In both conditions, there were four pairs of stimuli (i.e., reference-test separated by a 2-s pause), presented in different randomised order to each subject. This part of the study took approximately 5 minutes.

\subsubsection{Location of discomfort: Part 3}

In Part 3 of the study, subjects indicated where they felt discomfort while exposed to two levels (0.4 and $1.6 \mathrm{~ms}^{-2}$ r.m.s.) of each of the 14 frequencies while sitting with backrest contact as in Part 1. After the presentation of each test stimulus, subjects reported the location in their body that felt the most discomfort using a body map in front of them (see Figure 5 below). They were presented with 28 test stimuli in random order. This part of the study took approximately 7 minutes.

\subsubsection{Seat transmissibility: Part 4}

Part 4 of the study involved the measurement of the transmission of vibration through the seat pan and the backrest while exposed to four levels $\left(0.2,0.4,0.8\right.$ and $1.6 \mathrm{~ms}^{-2}$ r.m.s.) of 60-s broadband (1 to $20 \mathrm{~Hz}$ ) random vertical vibration when sitting with backrest contact (Figure 1a) and when sitting upright with no backrest (Figure 1c). This part of the study took approximately 10 minutes.

The transmissibility, $H(f)$, of each of the three compliant seats was calculated from the ratio of the cross-spectral density of the input and output acceleration, $S_{x y}(f)$, to the power spectral density of the input acceleration, $S_{x x}(f)$, with a frequency resolution of $0.25 \mathrm{~Hz}$ :

$$
H(f)=\frac{S_{x y}(f)}{S_{x x}(f)}
$$

Equation 1

The vertical transmissibility of the seat cushion was calculated from the input acceleration measured by an accelerometer on the vibrator platform and the output acceleration measured by an accelerometer in a SIT-pad on the seat cushion beneath the ischial tuberosities. The $x$-axis transmissibility of the backrest was calculated from the acceleration measured by an accelerometer on a rigid part of the rear of the backrest and the acceleration measured by an accelerometer in a SIT-pad positioned between the upper back and the foam backrest, with the sensitive axis of both accelerometers inclined 30 degrees to the horizontal. The z-axis transmissibility of the backrest was calculated from accelerometers at the same locations but inclined 30 degrees to the vertical. 


\subsection{Subjects}

Using a within-subject experimental design, 12 healthy male subjects participated in all four sessions (i.e., with the four seating conditions). Subjects had a mean age of 26 years (SD: 2.2), a mean stature of $1.76 \mathrm{~m}$ (SD: 8.8), and a mean weight of $73.7 \mathrm{~kg}$ (SD: 14.9). Subjects were students and staff of the University of Southampton with no history of any serious illness, injury, or disability that might affect their judgement of vibration.

The experiment was approved by the Human Experimentation Safety Ethics Committee of the Institute of Sound and Vibration Research at the University of Southampton. All subjects gave their voluntary consent prior to the start of their first session on each day.

\section{RESULTS}

\subsection{Subjective measurement}

\subsubsection{Rates of growth of discomfort, $n$}

For each frequency of vibration, the magnitude estimates of vibration discomfort, $\psi$, and the vibration magnitudes, $\varphi$, are assumed to be related by a power law (Stevens, 1975):

$$
\psi=k \varphi^{n}
$$

Equation 2

Individual values for the rate of growth of discomfort, $n$, and the constant, $k$, were determined from the slopes and intercepts of linear least squares regressions between $\log _{10} \psi$ and $\log _{10} \varphi$ at each frequency:

$$
\log _{10} \psi=n \log _{10} \varphi+\log _{10} k
$$

Equation 3

In each of the four seating conditions, the rate of growth of discomfort, $n$, was strongly dependent on the frequency of vibration ( $p<0.001$, Friedman; Figure 2$)$.

\section{Figure 2 ABOUT HERE}

The rate of growth of discomfort only differed between seating conditions at 4 and $5 \mathrm{~Hz}$ $(p<0.001$, Friedman). Six pairwise comparisons performed between the four seating conditions with an adjusted significant level $(p=0.05 / 6=0.008)$, showed the rates of growth of discomfort differed between the foam seats and the rigid seat: between the hard foam seat (C3) and the rigid seat at 4 and $5 \mathrm{~Hz}$, between the softer foam seats (C1 and C2) and the rigid seat at 4,5 and $6.3 \mathrm{~Hz}(p<0.008$, Wilcoxon). 


\subsubsection{Equivalent comfort contours within seating conditions}

Individual equivalent comfort contours were calculated at four sensation magnitudes $(\psi=80$, 100, 125 and 160, relative to 100 with 0.40 ms $^{-2}$ r.m.s. at $8 \mathrm{~Hz}$ ) using Equation 1 and individual $n$ and $k$ values at each frequency (Table 1). Median equivalent comfort contours were constructed from the medians of the 12 individual equivalent comfort contours at each of these four sensation magnitudes (Figure 3).

Table 1 and Figure 3 ABOUT HERE

As expected from the dependence of the rate of growth of discomfort, $n$, on the frequency of vibration and the seating conditions, the shapes of the equivalent comfort contours varied with the magnitude of vibration and the seating condition.

\subsubsection{Relative discomfort between seating conditions}

To determine the effect of seating condition on vibration discomfort, the vibration acceleration required in each seating condition to cause discomfort similar to that caused by the 'common reference between seating conditions' (i.e., $0.4 \mathrm{~ms}^{-2}$ r.m.s. at $8 \mathrm{~Hz}$ when sitting on the rigid seat with no backrest contact) was determined at each frequency. This was achieved by two adjustments to the equivalent comfort contours obtained within each seating condition. The equivalent comfort contour for each subject was first rescaled to the sensation magnitude of the 'common reference within each seating condition', using individual $n$ and $k$ values for the respective seating conditions as determined in Part 1 of the study. The rescaled equivalent comfort contours were then rescaled again to the sensation magnitude of the 'common reference between seating conditions', using individual values of $n$ with the rigid seat as determined in Part 2 of the study - assuming the same vibration acceleration at the interface between the body and a seat will produce similar vibration discomfort with a rigid seat and a compliant seat squab. The medians of these twelve individual 'rescaled' equivalent comfort contours were determined for each seating condition to yield the r.m.s. acceleration of the vibrator platform required with each seating condition at each frequency to cause similar discomfort to that caused by the 'common reference between seating conditions' (Figure 4a).

\section{Figure 4 ABOUT HERE}

\subsubsection{Location of discomfort}

With all frequencies and magnitudes of vibration and all seating conditions, subjects generally felt discomfort in their backs, shoulders, buttocks, or thighs: the body parts with greatest weight supported by the seat pan and the backrest (Figure 5). However, the number 
of subjects reporting discomfort in either their head or neck varied with frequency when sitting in the compliant seats with the greatest magnitudes of vibration, and when sitting in the rigid seat with the middle magnitudes of vibration ( $p<0.01$, Cochran's Q).

The number of subjects reporting discomfort in either their head or neck varied between seats at $10,12.5,16$, and $20 \mathrm{~Hz}$ when exposed to the greatest vibration magnitudes, and at $20 \mathrm{~Hz}$ when exposed to the middle magnitude $(p<0.01$, Cochran's Q). With the greatest vibration magnitude, the number of subjects reporting discomfort in either their head or neck differed between the rigid seat and each compliant seat $(p<0.05$, McNemar). More subjects reported discomfort in either their head or neck when sitting in the rigid seat but in either their lower legs or feet when sitting in the compliant seats.

Figure 5 ABOUT HERE

\subsubsection{Measured discomfort}

To quantify the effect of the different types of foam on vibration discomfort at each frequency, the ratios of the vibration acceleration required with each compliant seat, $a_{\text {compliant }}$, to the acceleration required with a rigid seat, $a_{\text {rigid, }}$ to cause similar discomfort to the 'common reference between seating conditions' (determined from Part 2 of the study, see Section 3.1.3) were calculated at each frequency (Figure $4 b$ ):

$$
\text { Ratio of accelerations (\%) }=\frac{a_{\text {compliant }}}{a_{\text {rigid }}} \times 100 \%
$$

Equation 4

To compare the measured and predicted seating discomfort, these acceleration ratios were inverted to have a similar meaning to a SEAT value, and are referred to as the 'measured seat dynamic discomfort', MSDD, in this paper:

Measured seat dynamic discomfort, MSDD $(\%)=\frac{1}{\text { Ratio of accelerations }} \quad$ Equation 5 A measured seat dynamic discomfort, MSDD, of $100 \%$ would imply similar discomfort as when sitting on the rigid seat. Percentages lower or higher than $100 \%$ indicate less or more discomfort than with the rigid seat, respectively.

The seat foam had a large effect on vibration discomfort. The MSDD differed between seating conditions at frequencies from 6.3 to $20 \mathrm{~Hz}(p<0.001$, Friedman: Figure 6). The MSDD with seats $C 1$ and $C 2$ was less than with the rigid seat at all frequencies from 6.3 to $20 \mathrm{~Hz}$ ( $p<0.008$, Wilcoxon). The MSDD of seat C3 was greater than that of the rigid seat at 4 $\mathrm{Hz}$ and $5 \mathrm{~Hz}(p<0.008$, Wilcoxon) but less than the rigid seat at all frequencies from 8 to 16 $\mathrm{Hz}(p<0.008$, Wilcoxon). There were no differences in the MSDD between seats $\mathrm{C} 1$ and $\mathrm{C} 2$ 
at any frequency ( $p>0.05$, Wilcoxon). However, the MSDD of seat C1 was less than that seat C3 at all frequencies greater than $6.3 \mathrm{~Hz}$, and the MSDD of seat C2 was less than that of seat $\mathrm{C} 3$ at all frequencies between 5 and $20 \mathrm{~Hz}(p<0.008$, Wilcoxon).

Figure 6 ABOUT HERE

\subsection{Objective measurement and evaluation}

\subsubsection{Foam seating dynamics}

The primary resonance frequency in the seat cushion transmissibility differed between the foams ( $p<0.001$, Friedman). The differences were between the resonance frequency with C3 (hard foam) and the two softer seats ( $p<0.01$, Wilcoxon). The median resonance frequencies were $3.5,3.75$, and $4.25 \mathrm{~Hz}$ with $\mathrm{C} 1, \mathrm{C} 2$ and $\mathrm{C} 3$ respectively (Table 2).

Figure 7 ABOUT HERE

Table 2 ABOUT HERE

The transmissibility at resonance also differed between the foams $(p<0.001$, Friedman), with the difference between $\mathrm{C} 3$ and the other two compliant seats ( $p<0.05$, Wilcoxon). The median amplification at resonance was 20 to $23 \%$ greater with C1 and C2 than with C3 (Table 2).

With seat $\mathrm{C} 3$, there was a secondary resonance around 7 to $8 \mathrm{~Hz}$, and a median transmissibility consistently greater than the other two compliant seats at all frequencies greater than the resonance frequency (Figure 7a).

The backrest condition did not significantly affect the resonance frequency or the transmissibility at resonance in any of the compliant seats ( $p>0.05$; Friedman; Figure 8). However, compared to sitting upright with no backrest, the transmissibility was reduced when sitting with the back in contact with the backrest at frequencies between 0.75 and 3.5 $\mathrm{Hz}$ with all three seats $(p<0.05$, Wilcoxon), but increased at frequencies between 4.5 and 9 $\mathrm{Hz}$ with seat $\mathrm{C} 1$ and between $4.5 \mathrm{~Hz}$ and 10.25 with seat $\mathrm{C} 2$. With seat $\mathrm{C} 3$, when sitting with the back in contact with the backrest the transmissibility was increased at frequencies between 5 and $8.5 \mathrm{~Hz}$ and reduced at frequencies between 11.25 and $20 \mathrm{~Hz}(p<0.05$, Wilcoxon).

\section{Figure 8 ABOUT HERE}

Floor to $x$-back transmissibility differed between the three foam seats at some frequencies, but the trend was similar with the median transmissibility exhibiting two peaks: a primary 
peak around $4 \mathrm{~Hz}$ and a secondary peak in the range 6 to $8 \mathrm{~Hz}$ (Figure $7 \mathrm{~b}$ ). The median $x$ back transmissibility of seat C3 was consistently higher at frequencies around resonances, and lower at frequencies greater than about $11 \mathrm{~Hz}$ than with the other compliant seats (Figure 7b): the transmissibility was greater for seat C3 than seat C1 at frequencies between 7 and $9 \mathrm{~Hz}$, and greater than seat $\mathrm{C} 2$ at $7.75 \mathrm{~Hz}(p<0.017$, Wilcoxon, adjusted significance, $p=0.05 / 3=0.017$ ). However, the transmissibility of seat C3 was only significantly less than that of seat C2 at frequencies between 11 and $13.75 \mathrm{~Hz}(p<0.017$, Wilcoxon).

The trends in the floor to $z$-back transmissibility were similar with all seats: a slight resonance around $4 \mathrm{~Hz}$, slight attenuation between 6 and $10 \mathrm{~Hz}$, and amplification at frequencies greater than about $10 \mathrm{~Hz}$ (Figure 7c). The resonance in seat C3 was at the slightly higher frequency of $4.25 \mathrm{~Hz}$ than the other foam seats, with an amplification of 1.28 (Table 2).

\subsubsection{Predicted discomfort (SEAT values)}

For each compliant seat, the SEAT value was calculated for each frequency of vibration from the ratio of the overall ride values with the compliant seat, $a_{w}$ compliant, to the overall ride value with the rigid seat, $a_{w}$ rigid (Figure 9):

$$
\operatorname{SEAT}(\%)=\frac{a_{\mathrm{w} \text { compliant }}}{a_{\mathrm{w} \text { rigid }}} \times 100 \%
$$

Equation 6

The SEAT value of a seat is calculated using the vibration to which the seat is exposed, usually a complex spectrum of vibration in a vehicle. In the present study, the subjects were exposed to sinusoidal vertical vibration at each frequency and so the SEAT value was calculated for each frequency so that it could be compared with subject judgements of vibration discomfort at that frequency.

A SEAT value is often calculated for only one part of a seat (e.g., the seat squab) and only one direction of vibration (e.g., vertical). The discomfort of subjects in this study may have been affected by vibration at other locations (i.e., at the seat back and the feet). Although the input vibration was vertical, there was both vertical and fore-and-aft vibration at the backrest. The SEAT value was therefore calculated from 'overall ride values' so as to reflect the differences in vibration at the seat, the back, and the feet between the compliant seat and the rigid seat when sitting with backrest contact.

The overall ride values were calculated according to BS 6841 (1987) from the square-root of the sums-of-squares (r.s.s.) of the frequency-weighted root-mean-square accelerations at the seat, the back, and the feet (Table 3): 


$$
a_{w}=\left(\left(k_{\text {seat }} \times a_{\text {seat }} \cdot W_{\text {seat }}\right)^{2}+\left(k_{\text {back }} \times a_{\text {back }} \cdot W_{\text {back }}\right)^{2}+\left(k_{\text {feet }} \times a_{\text {feet }} \cdot W_{\text {feet }}\right)^{2}\right)^{1 / 2} \quad \text { Equation } 7
$$

where,

$a_{i}=$ acceleration at input location, $i$

$W_{i}=$ frequency weighting for input location, $i$

$k_{i}=$ multiplying factor for input location, $i$

\section{Figure 9 ABOUT HERE}

\section{Table 3 ABOUT HERE}

The SEAT values (i.e., the predicted discomfort) were dependent on seating condition at all frequencies ( $p<0.02$, Friedman: Figure 10). The SEAT values for each of the compliant seats differed from those for the rigid seat at all frequencies except at a cross-over frequency $(p<0.008$, Wilcoxon). With seats $\mathrm{C} 1$ and $\mathrm{C} 2$ the SEAT values were greater than with the rigid seat at all frequencies less than $6.3 \mathrm{~Hz}$ but less than with the rigid seat at higher frequencies. With seat C3 the SEAT values were greater than with the rigid seat at all frequencies less than $8 \mathrm{~Hz}$ but less than with the rigid seat at all frequencies greater than 10 $\mathrm{Hz}$. There were no significant differences in the SEAT values between $\mathrm{C} 1$ and $\mathrm{C} 2$ seat at any frequency except $2.5 \mathrm{~Hz}$ and $10 \mathrm{~Hz}$ ( $p<0.05$, Wilcoxon). There were significant differences between these two compliant seats and seat $C 3$, with the SEAT values of seats $\mathrm{C} 1$ and $\mathrm{C} 2$ greater at all frequencies less than $4 \mathrm{~Hz}$ but less at all frequencies greater than $6.3 \mathrm{~Hz}(p<0.008$, Wilcoxon).

Figure 10 ABOUT HERE

\subsection{Measured and predicted seating discomfort}

For each of the three compliant seats, the measured seat dynamic discomfort (i.e., MSDD) was broadly similar to the predicted seat discomfort (i.e., SEAT value), but there were significant differences (Figure 11). With seat $\mathrm{C} 1$, the SEAT prediction overestimated discomfort at 1.25 and $3.15 \mathrm{~Hz}$ and at all frequencies greater than $5 \mathrm{~Hz}$, except $16 \mathrm{~Hz}$ $(p<0.05$, Wilcoxon, Figure $11 \mathrm{a})$. With seat $\mathrm{C} 2$, the prediction significantly overestimated discomfort at all frequencies except 1.6, 2.5, 4 and $5 \mathrm{~Hz}(p<0.05$, Wilcoxon, Figure 11b). With seat $\mathrm{C} 3$, the prediction significantly overestimated discomfort at frequencies between 6.3 and $16 \mathrm{~Hz}(p<0.05$, Wilcoxon, Figure 11c).

Figure 11 ABOUT HERE 


\section{DISCUSSION}

\subsection{Effect of seat compliance}

The measured discomfort when sitting in the three foam seats was greatest at $4 \mathrm{~Hz}$ (Figure 6). At this frequency, when sitting on the rigid seat a $40 \%$ greater vibration magnitude was required at the floor to get discomfort similar to that with seats $\mathrm{C} 1$ and $\mathrm{C} 2$ and an $80 \%$ greater magnitude was required with seat $\mathrm{C} 3$. This was due to the resonance of the humanseat system when sitting on the foam: the floor-to-seat vertical transmissibility (Figure 7a) and the floor-to-back $x$-axis transmissibility (Figure $7 \mathrm{~b}$ ) were greatest around 3.5 to $4.5 \mathrm{~Hz}$ (Table 2). Amplification of vibration at the seat surface also produced movement in shear between the back and the backrest, as seen by comparing z-axis floor-to-seat and floor-toback transmissibilities (Figures $7 \mathrm{a}$ and $7 \mathrm{c}$ ), causing discomfort in the lower back and the upper back (Figure 5).

In all three foam seats, the least measured discomfort occurred at frequencies greater than $10 \mathrm{~Hz}$ (Figure 6). At these frequencies, for similar discomfort when sitting on the rigid seat about $80 \%$ less vibration was required at the floor than when sitting on seats $C 1$ and $C 2$, and $50 \%$ less vibration was required than when sitting on seat C3. The combined dynamic properties of the human body and the foams resulted in vibration isolation at frequencies greater than about $6 \mathrm{~Hz}$ with seats $\mathrm{C} 1$ and $\mathrm{C} 2$ and at frequencies greater than about $8 \mathrm{~Hz}$ with seat C3 (Figure 7a, Table 2). The isolation provided by seat C3 was less than provided by the other two compliant seats: the vibration at the seat surface was $25 \%$ or more with seat $\mathrm{C} 3$ than with seats $\mathrm{C} 1$ and $\mathrm{C} 2$ at all frequencies greater than $8 \mathrm{~Hz}$ (Figure 7a). This will have contributed to the greater discomfort experienced with seat C3 than with seats C1 and $\mathrm{C} 2$ at these frequencies.

High frequencies of vibration tend to cause discomfort at locations in the body close to the source of vibration (Whitham and Griffin, 1978). The greater sensitivity to vertical vibration at the seat and to vertical vibration at the backrest than to vertical vibration at the feet (Griffin et al., 1982) is consistent with more subjects reporting discomfort in the buttocks, thighs, lower back or upper back with the rigid seat than with the three compliant seats. The foam reduced high frequency vibration at the seat and the backrest by more than $50 \%$ (Figure $7 \mathrm{a}$ and $7 \mathrm{~b}$ ), leaving vibration at the feet a more dominant source of discomfort and more subjects reporting discomfort in either their feet of lower legs at high frequencies with the compliant seats than with the rigid seat (Figure 5). 


\subsection{Effect of backrest contact}

Comparing the median z-axis floor-to-seat transmissibilities with and without subjects leaning against the backrest (Figure 8), it can be seen that contact with the backrest tended to increase the vibration transmitted through the seat cushion at frequencies between about 4 and $9 \mathrm{~Hz}$, consistent with Corbridge and Griffin (1989). In part, this might arise because movement of the upper-body induced by the backrest is transmitted to the lower-body and the seat surface, consistent with a resonance of the upper-body between 4 and $8 \mathrm{~Hz}$ in the $x$-axis of the back (Figure $7 b$ ). Contact with a backrest may also change the dynamic response of the body (e.g., the vertical apparent mass measured at the seat) and the combined dynamic response of the seat-body system (Toward and Griffin, 2009).

\subsection{The efficiency of the SEAT prediction model}

The usefulness of SEAT values can be examined by comparing them with the measured discomfort at each frequency. The contributions to the overall ride value from each component ride value (i.e., the weighted acceleration at the seat, the back, and the feet) were calculated for the three compliant seats and the rigid seat so as to examine possible reasons for differences between the SEAT values and the measured discomfort (Figure 12).

Figure 12 ABOUT HERE

The SEAT values were greater than the measured discomfort at low frequencies (i.e., 1.25 to $3.15 \mathrm{~Hz}$ ) with seats $\mathrm{C} 1$ and $\mathrm{C} 2$, and at high frequencies (i.e., at frequencies greater than about $6.3 \mathrm{~Hz}$ ) with all three compliant seats. The differences may be understood by simplifications in the standardised method of predicting discomfort (i.e., assuming the weightings are unaffected by the inclination of the backrest and assuming that relative motion between the seat and the feet does not contribute to discomfort; Jang and Griffin, 2000).

With a single frequency of excitation and a single point of contact with vibration on a seat, the SEAT value is the same as the seat transmissibility. The same frequency weighting is applied to the vibration on the seat and the vibration entering the seat. With multiplefrequency vibration, the SEAT value is comprised of more than one frequency component and the frequency weighting influences the overall SEAT value. With multiple-input vibration, the SEAT value is comprised of more than one input and the relative weighting of each input influences the overall SEAT value. In the present case, with single-frequency vibration transmitted to the seat, the back, and the feet, if the ratios of the weightings between these inputs are incorrect, the overall SEAT value will also be incorrect. However, the direction of the error in the SEAT value will depend on whether the magnitude of vibration at any point is 
greater than, or less than, with a rigid seat. If the vibration transmitted to any location is greater than with a rigid seat (i.e., the transmissibility is greater than 1.0), the SEAT value will be over-estimated if the weighting is too great. If the vibration transmitted to any location is less than with a rigid seat (i.e., the transmissibility is less than 1.0), the SEAT value will be under-estimated if the weighting is too great. In the present study, the greatest errors in SEAT values will therefore tend to occur at the frequencies where foam increased the transmission of vibration to the body (e.g., around $5 \mathrm{~Hz}$ ) or where the foam decreased the transmission of vibration to the body (e.g., from 8 to $20 \mathrm{~Hz}$ ).

\section{Effect of backrest inclination on the frequency weighting for vertical seat vibration}

At $3.15 \mathrm{~Hz}$ there was no significant difference in the measured discomfort between the three compliant seats (see Section 3.1.3, Figure 4a). However, the discomfort predicted by the SEAT values was greater than the measured discomfort with seats $\mathrm{C} 1$ and $\mathrm{C} 2$ but not with seat C3 (Figure 11). At $3.15 \mathrm{~Hz}$, the floor-to-seat transmissibilities of seats C2 and C3 were greater than that of seat $\mathrm{C} 3$ (Figure 7a). Vertical vibration at the seat (i.e., the $z$-seat component ride value in Figures $12 \mathrm{a}$ and $12 \mathrm{~b}$ ) was the main contributor to the increased SEAT value for these two seats. With frequencies around $5 \mathrm{~Hz}$, more vertical seat vibration (approximately $50 \%$ more) is required to cause discomfort when a backrest is inclined at $30^{\circ}$ than with an upright backrest (Basri and Griffin, 2012). Use of the standardised weighting (i.e., $W_{\mathrm{b}}$ with $k=1.0$ ) to evaluate vertical vibration on the seat squab with inclined backrests in this study would therefore overestimate discomfort, consistent with the SEAT values being greater than the measured discomfort. With greater seat transmissibility, the overestimate will be greater, as seen with seats $\mathrm{C} 1$ and $\mathrm{C} 2$.

\section{Effect of backrest inclination on the frequency weighting for $x$-axis back vibration}

The foam amplified $x$-axis vibration at the back between 4 and $8 \mathrm{~Hz}$ but attenuated vibration at frequencies greater than about $8 \mathrm{~Hz}$ (Figure 7b). The amplification of $x$-axis backrest vibration at some frequencies (i.e., $<8 \mathrm{~Hz}$; Figure 7b) may have contributed to increased discomfort in the range 2.5 to $8 \mathrm{~Hz}$ (Figure 6), although a greater influence over this frequency range was probably the amplification of $z$-axis vibration transmitted to the seat (Figure 7a).

Around 4 to $6.3 \mathrm{~Hz}$, the discomfort caused by $x$-axis vibration of a backrest reduces by 30 to $40 \%$ when a backrest is reclined from $0^{\circ}$ (i.e., vertical) to $30^{\circ}$ (Basri and Griffin, 2011). The $W_{\mathrm{c}}$ weighting for $x$-axis acceleration of the back therefore overestimates discomfort at these frequencies when there is a $30^{\circ}$ inclination of a backrest, as in the present study. With greater acceleration on the backrests of the compliant seats than the rigid seat, the use of 
the $W_{\mathrm{c}}$ weighting will have over-emphasised fore-and-aft backrest vibration and contributed to the greater predicted discomfort (i.e., greater SEAT values) than measured discomfort.

At frequencies greater than about $6.3 \mathrm{~Hz}$, there was more discomfort from vibration when sitting in the rigid seat than when sitting in any of the three compliant seats. The attenuation of $x$-axis backrest vibration at frequencies of high sensitivity to $x$-axis backrest vibration will have reduced discomfort in the compliant seats compared to the rigid seat. Kato and Hanai (1998) reported the discomfort of $x$-axis vibration of an inclined backrest would be underestimated by 40 to $50 \%$ when using the $W_{c}$ weighting at frequencies greater than $8 \mathrm{~Hz}$. The $x$-axis vibration at the interface between the back and the backrest was very much less with the three compliant seats than with the rigid seat (the floor to $x$-back transmissibility was around 0.5 ; Figure $7 \mathrm{~b}$ ). If the $x$-axis back vibration was given greater weight (as implied by Kato and Hanai, 1998), it would contribute more to the overall ride value, with a greater increase in the rigid seat than in the compliant seats. This would reduce the SEAT values in the compliant seats so that they were more similar to the measured discomfort.

\section{Vibration of the feet}

As the frequency of vibration increased above about $8 \mathrm{~Hz}$, the vibration of the feet became an increasingly important cause of discomfort in the compliant seats, but not the rigid seat (Figure 5). This is consistent with the dominant contribution to the SEAT values at high frequencies coming from the vibration at the feet when sitting on the compliant seats but not on rigid seat (Figure 12). The weighted acceleration at the feet changed little over the range 5 to $20 \mathrm{~Hz}$, but the vibration of the feet became more important as the weighted acceleration from other inputs reduced as the frequency of the vibration increased. Similarly, although the acceleration at the feet was the same for the compliant seats and the rigid seat, the vibration at the feet was of greater importance in the compliant seats due to the lower magnitudes of vibration at other locations.

\section{Overview}

Seat compliance changes the dynamic response of the seat-body system and the discomfort caused by vertical vibration. Resonance of a seat cushion in the region of $4 \mathrm{~Hz}$ increases vibration discomfort, whereas attenuation of vibration at higher frequencies decreases vibration discomfort, with the increases and decreases in discomfort dependent on the compliance of the seat cushion. Attenuation of high frequency vibration at the seat and the backrest leaves vibration at the feet a more dominant source of vibration discomfort. Contact with a compliant vibrating backrest produces vibration of the upper-body that is transmitted to the lower-body and the seat squab. Vertical vibration of a compliant seat squab produces vibration of the lower-body that results in shear motion between the back and the backrest. 
The application of the results of the study should recognise that other factors, including differences between subjects (e.g., gender and the extremes of age and body size) may influence the dependence of both vibration discomfort and the compliance of the seating on the frequency of vibration and the location of contact with vibration.

\section{CONCLUSIONS}

Useful predictions of how the compliance of seats with backrests influence the discomfort caused by vertical vibration are provided by SEAT values determined from overall ride values that take into account the discomfort caused by vibration at the seat, the back, the feet, and any other source.

Differences in the present study between SEAT values and subjective judgements of discomfort over the range 1.0 to $20 \mathrm{~Hz}$ can be explained by known assumptions and simplifications in currently standardised methods of predicting vibration discomfort. The discrepancies are likely to be partially due to the use of frequency weightings for vertical (i.e., $z$-axis) seat vibration and fore-and-aft (i.e., $x$-axis) back vibration that do not take into account the influence of the inclination of the backrest on the frequency-dependence of vibration discomfort at the seat and the backrest.

\section{ACKNOWLEDGEMENT}

The authors are grateful for the support from the Ministry of Higher Education of Malaysia and Universiti Teknikal Malaysia, Melaka. The authors also wish to thank Dr Chris Lewis and Dr Miyuki Morioka for providing software used to control the experiment. 


\section{REFERENCES}

Basri, B. and Griffin, M.J., 2011. The vibration of inclined backrests: perception and discomfort of vibration applied normal to the back in the $x$-axis of the body. Journal of Sound and Vibration, 330 (18-19), 4646-4659.

Basri, B. and Griffin, M.J., (2012). Equivalent comfort contours of vertical seat vibration: effect of vibration magnitude and backrest inclination. Ergonomics, 55 (8), 909-922.

Basri, B. and Griffin, M.J., (2013). Predicting discomfort from whole-body vertical vibration when sitting with an inclined backrest. Applied Ergonomics, 44 (3), 423-434.

British Standards Institution BS 6841, 1987. Guide to measurement and evaluation of human exposure to whole-body mechanical vibration and repeated shock.

Corbridge, C., Griffin, M.J. and Harborough, P.R., 1989. Seating dynamics and passenger comfort. Proceedings Institute of Mechanical Engineers, Part F: Journal of Rail and Rapid Transit, 203, 57-64.

Griffin, M.J., 1978. The evaluation of vehicle vibration and seats. Applied Ergonomics, 9 (1), 15-21.

Griffin, M.J., 2007. Discomfort from feeling vehicle vibration. Vehicle System Dynamics 45 (7-8), 679-698.

Griffin, M.J., Parsons, K.C. and Whitham, E., 1982. Vibration and comfort IV. Application of experimental results. Ergonomics, 25 (8), 721-739.

Griffin, M.J., 1990. Handbook of Human Vibration. Academic Press, London. ISBN: 0-12303040-4.

International Organization of Standardization ISO 2631, 1974. Guide for the evaluation of human exposure to whole-body vibration. International Organisation for Standardization, Geneva.

International Organization for Standardization ISO 10326-1, 1992. Mechanical vibration Laboratory method for evaluating vehicle seat vibration - Part 1: Basic requirements. International Organisation for Standardization, Geneva.

International Organization of Standardization ISO 2631-1, 1997. Mechanical vibration and shock - evaluation of human exposure to whole-body vibration - part 1: general requirements. International Organisation for Standardization, Geneva.

International Organization for Standardization ISO 7096, 2000. Earth-moving machinery Laboratory evaluation of operator seat vibration. International Organisation for Standardization, Geneva.

Jang, H.-K, Griffin, M.J., 2000. Effect of phase, frequency, magnitude and posture on discomfort associated with the differential vertical vibration at the seat and feet. Journal of Sound and Vibration 229 (2), 273-286.

Kato, K. and Hanai, T., 1998. The effect of backrest angles on discomfort caused by foreand-aft back vibration. Industrial Health 36, 107-111.

Pheasant, S., 1990. Bodyspace: Anthropometry, Ergonomics and the Design of Work. 2nd. ed., Taylor \& Francis.

Qiu, Y. and Griffin, M.J., 2003. Transmission of fore-aft vibration to a car seat using field test and laboratory simulation. Journal of Sound and Vibration, 264 (1), 135-155.

Stevens, S.S., 1975. Psychophysics: Introduction to its perceptual, neural, and social prospects, New York: John Wiley \& Sons, Inc. 
Toward, M.G.R.T. and Griffin, M.J., 2009. Apparent mass of the human body in the vertical direction: Effect of seat backrest. Journal of Sound and Vibration, 327, 657-669. doi: 10.1016/j.jsv.2009.07.012.

Whitham, E.M. and Griffin, M.J., 1978. The effect of vibration frequency and direction on the location of areas of discomfort caused by whole-body vibration. Applied Ergonomics, 9 (4), 231-239. 


\section{FIGURE LEGENDS}

Figure 1 Seating conditions. Sitting with the back leaning comfortably against inclined backrest of compliant seat (a) and rigid seat (b). Sitting upright without backrest contact for compliant seat (c) and rigid seat (d).

Figure 2 Medians and inter-quartile ranges of the rates of growth of discomfort for vertical vibration at the vibrator platform with each seating condition (a-d), and comparison of the medians with all seating conditions (e).

Figure 3 Median equivalent comfort contours for four magnitude estimates ( $\psi=80$ to 160) with each seating condition, where 100 corresponds to the discomfort caused by $0.4 \mathrm{~ms}^{-2}$ r.m.s. 8-Hz vertical vibration at the vibrator platform.

Figure 4 Relative discomfort between seating conditions: (a) contours indicate the median vibration acceleration at the vibrator platform required to produce discomfort equivalent to $0.4 \mathrm{~ms}^{-2}$ r.m.s. of $8-\mathrm{Hz}$ vertical vibration at vibrator platform when sitting upright on a rigid seat with no backrest contact; (b) contours indicate the ratio of vibration acceleration at the vibrator platform with each foam seat to that with the rigid seat required to cause discomfort equivalent to $0.4 \mathrm{~ms}^{-2}$ r.m.s. of $8-\mathrm{Hz}$ vertical vibration with the rigid seat.

Figure 5 Principal locations of discomfort in the body caused by $0.4 \mathrm{~ms}^{-2}$ r.m.s. and $1.6 \mathrm{~ms}^{-2}$ r.m.s. vertical vibration at each frequency with all seats.

Figure 6 Median measured discomfort for each seat (\%) derived from inversed ratio of accelerations at each frequency $(100 \%$ implies discomfort similar to that of with the rigid seat; percentages higher or lower than $100 \%$ indicate more or less vibration discomfort than with the rigid seat, respectively).

Figure 7 Median transmissibilities from floor to seat, floor to $x$-back, and floor to $z$-back for the foam cushions. Measured using $0.4 \mathrm{~ms}^{-2}$ r.m.s. random vertical vibration at the vibrator platform.

Figure 8 Median transmissibilities from floor to seat with and without backrest contact for each seat.

Figure 9 Schematic model for predicting vibration discomfort: the concept of SEAT (Seat Effective Amplitude Transmissibility) used in this study.

Figure 10 Median SEAT values for each seat (\%) indicating the ratio of the likely discomfort with each seat to that of with the rigid seat at each frequency $(100 \%$ indicates the likely discomfort is similar to that with the rigid seat; percentages higher or lower than $100 \%$ predict more or less vibration discomfort than with the rigid seat).

Figure 11 Comparison of median measured discomfort and predicted discomfort (SEAT values) at each frequency for each seat.

Figure 12 Median SEAT values and breakdown of their corresponding component ride values (in weighted r.m.s. acceleration) with rigid and compliant seats, compared to the median measured discomfort at each frequency. 


\section{TABLE LEGENDS}

Table 1 Median exponents $(n)$ and constants $(k)$ for seats $C 1, C 2$, and C3 and the rigid seat.

Table 2 Median primary resonance frequency and transmissibility at resonance for floor to seat, floor to $x$-back, and floor to $z$-back for seats C1, C2, and C3.

Table 3 Frequency weighting and axis multiplying factors from BS 6841:1987 used for calculating SEAT values. 
FIGURE 1
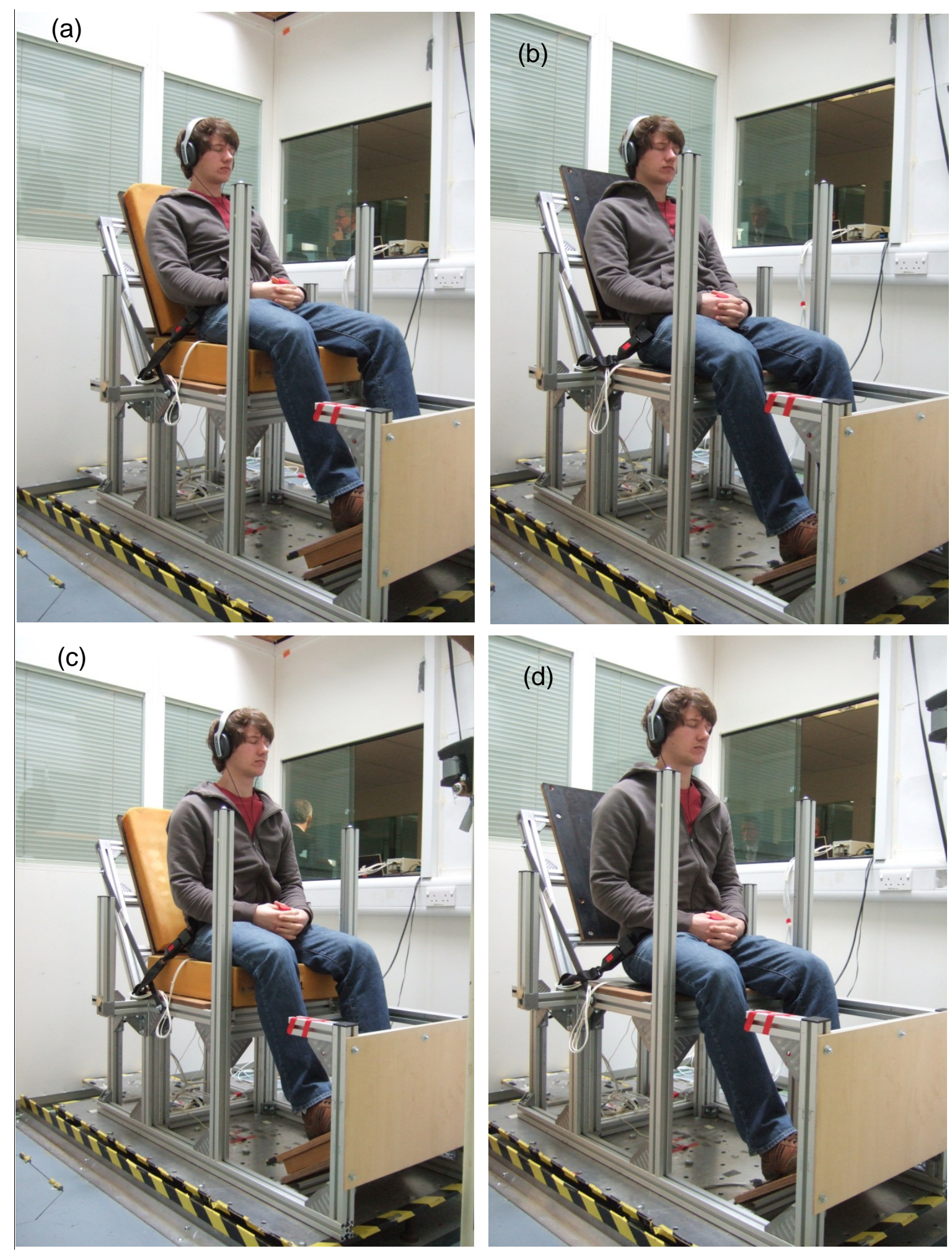
FIGURE 2

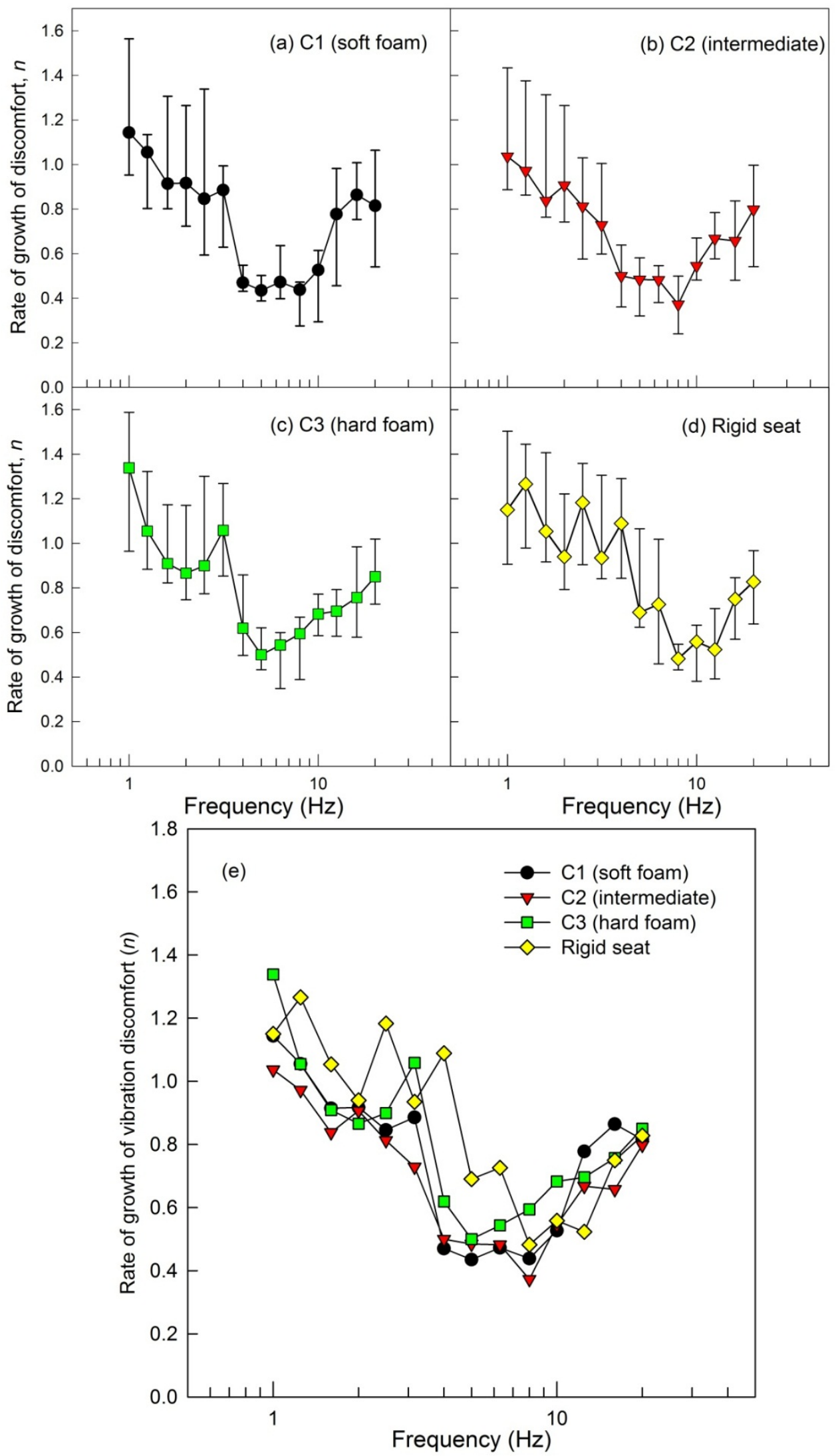




\section{FIGURE 3}

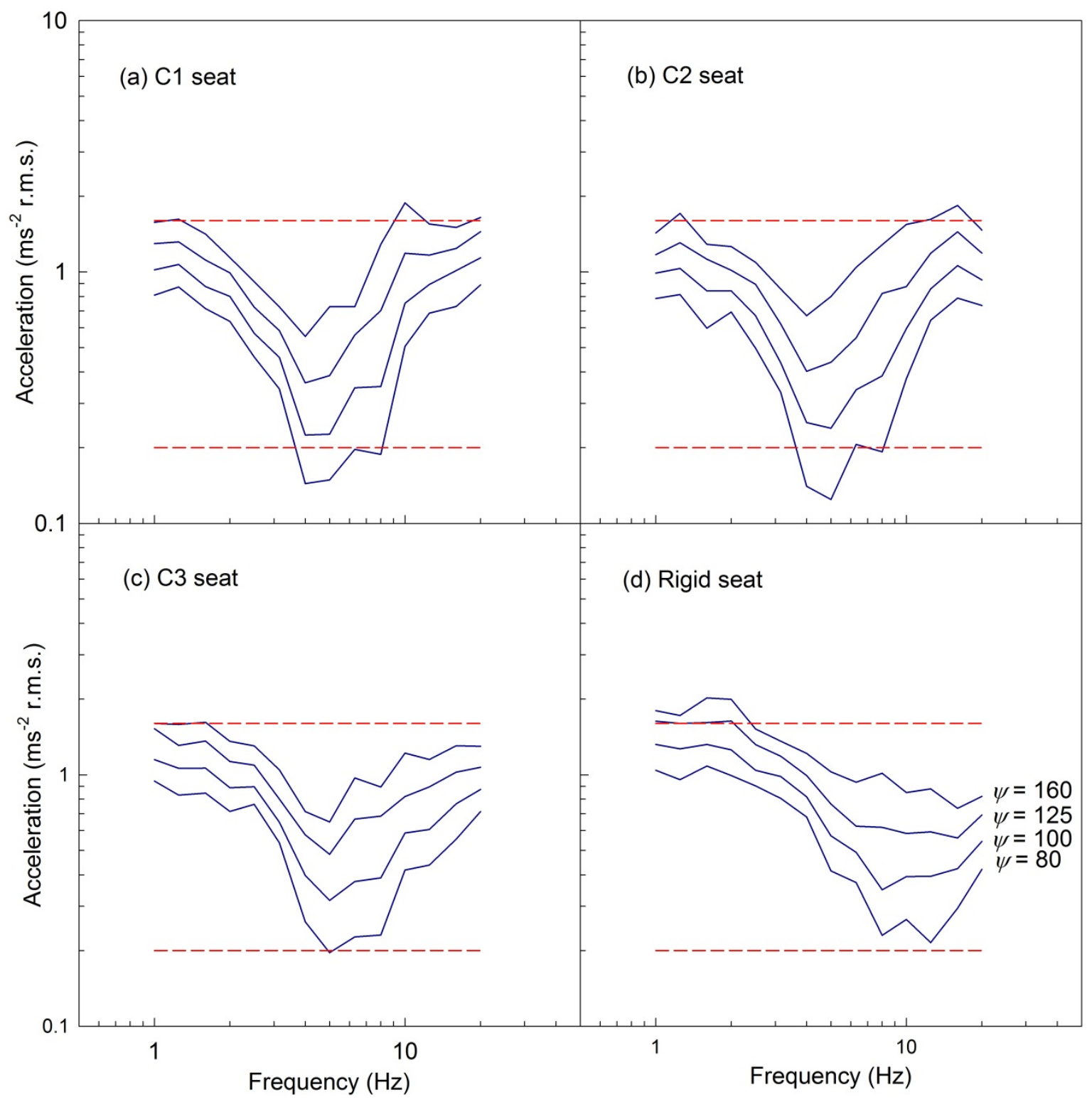


FIGURE 4
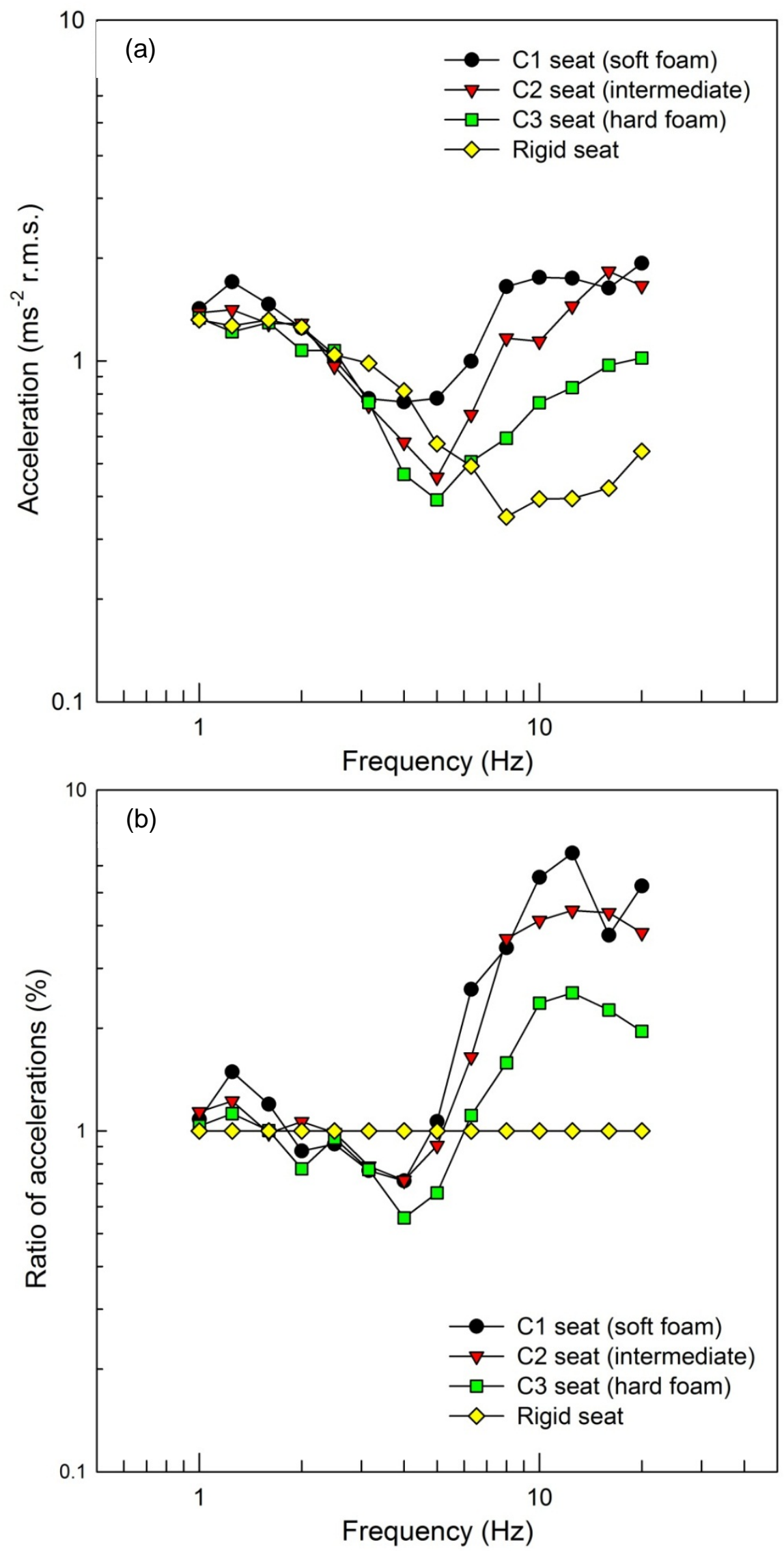


\section{FIGURE 5}
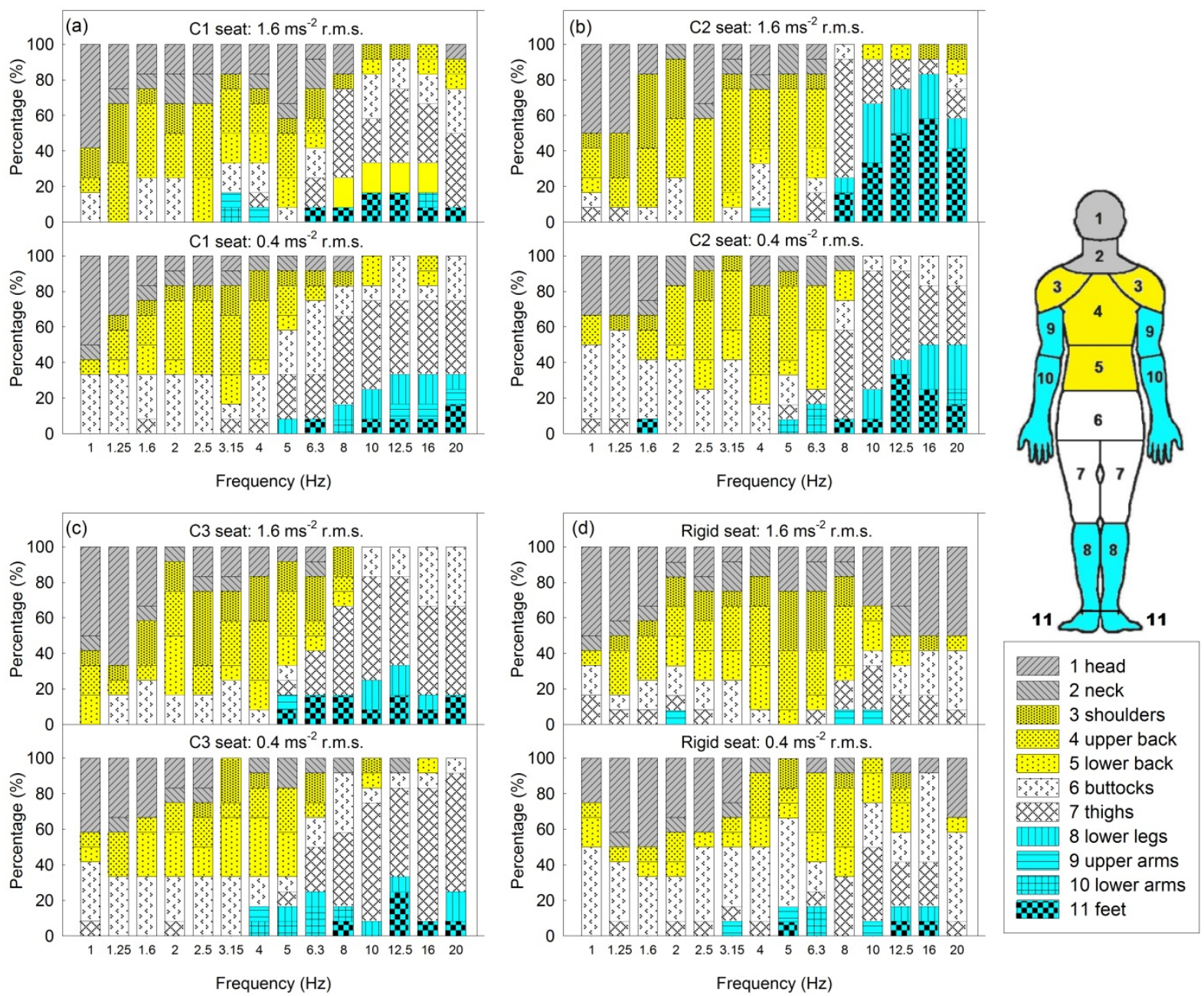

Frequency $(\mathrm{Hz})$ 
FIGURE 6

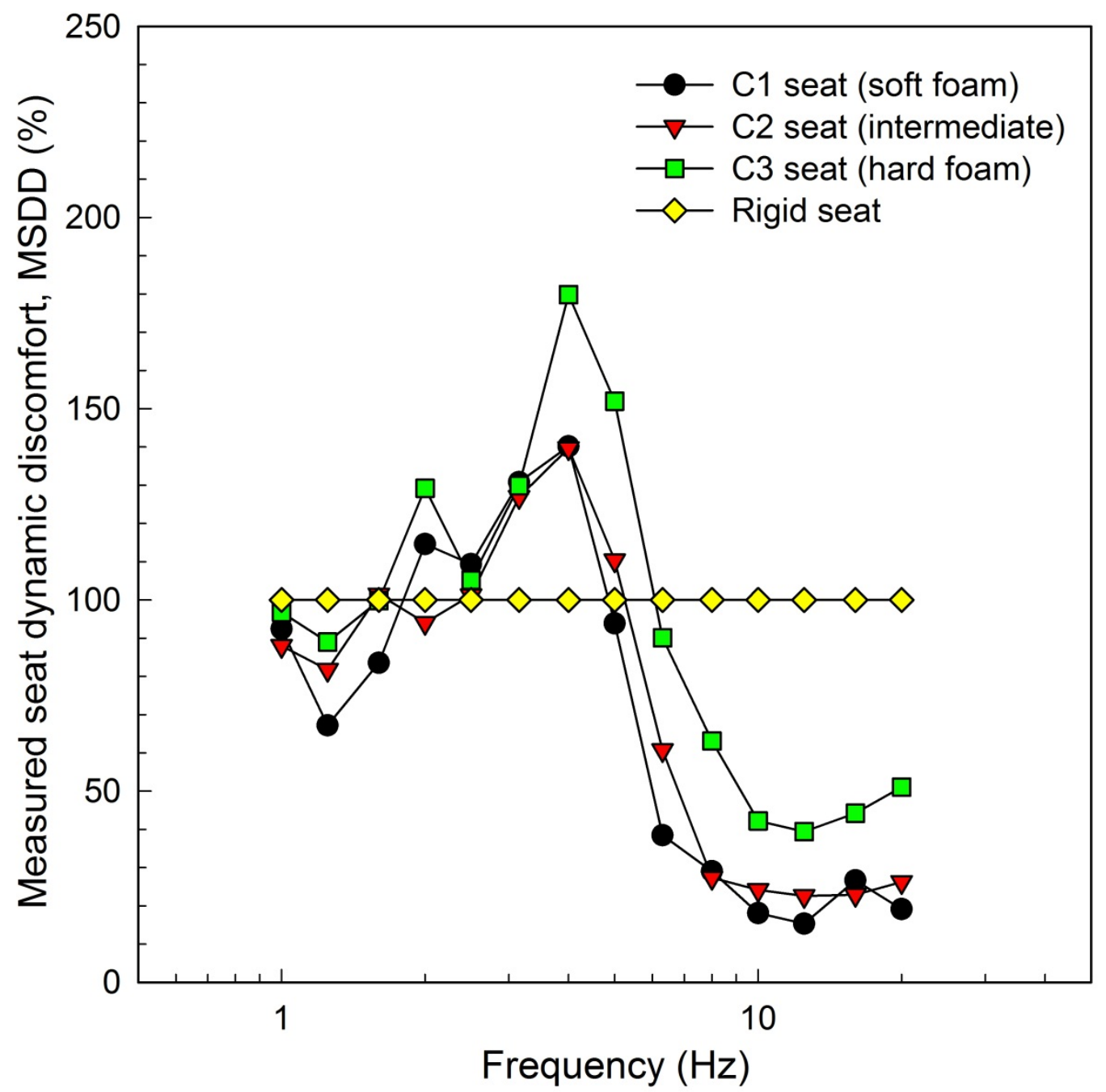


FIGURE 7

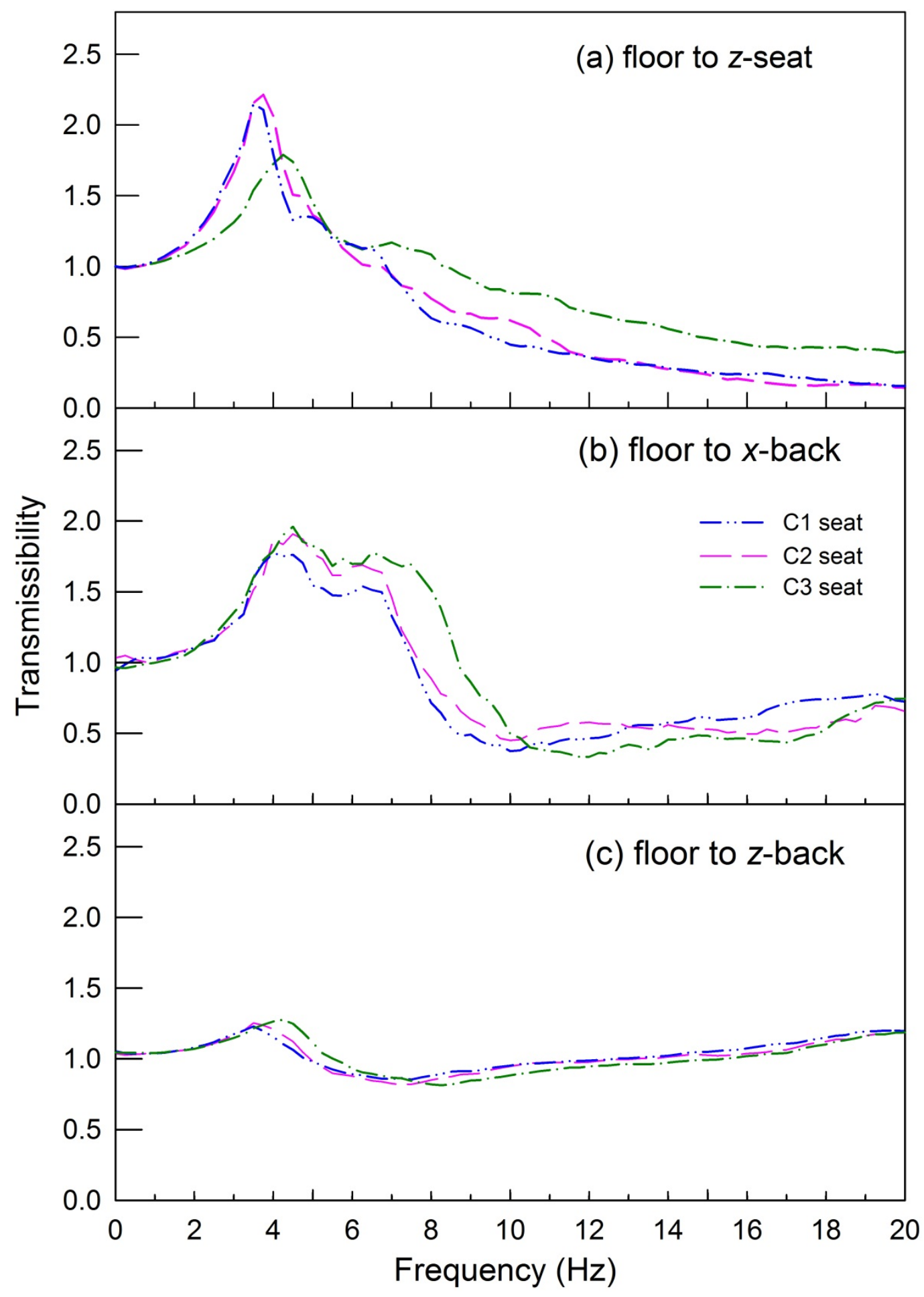


FIGURE 8

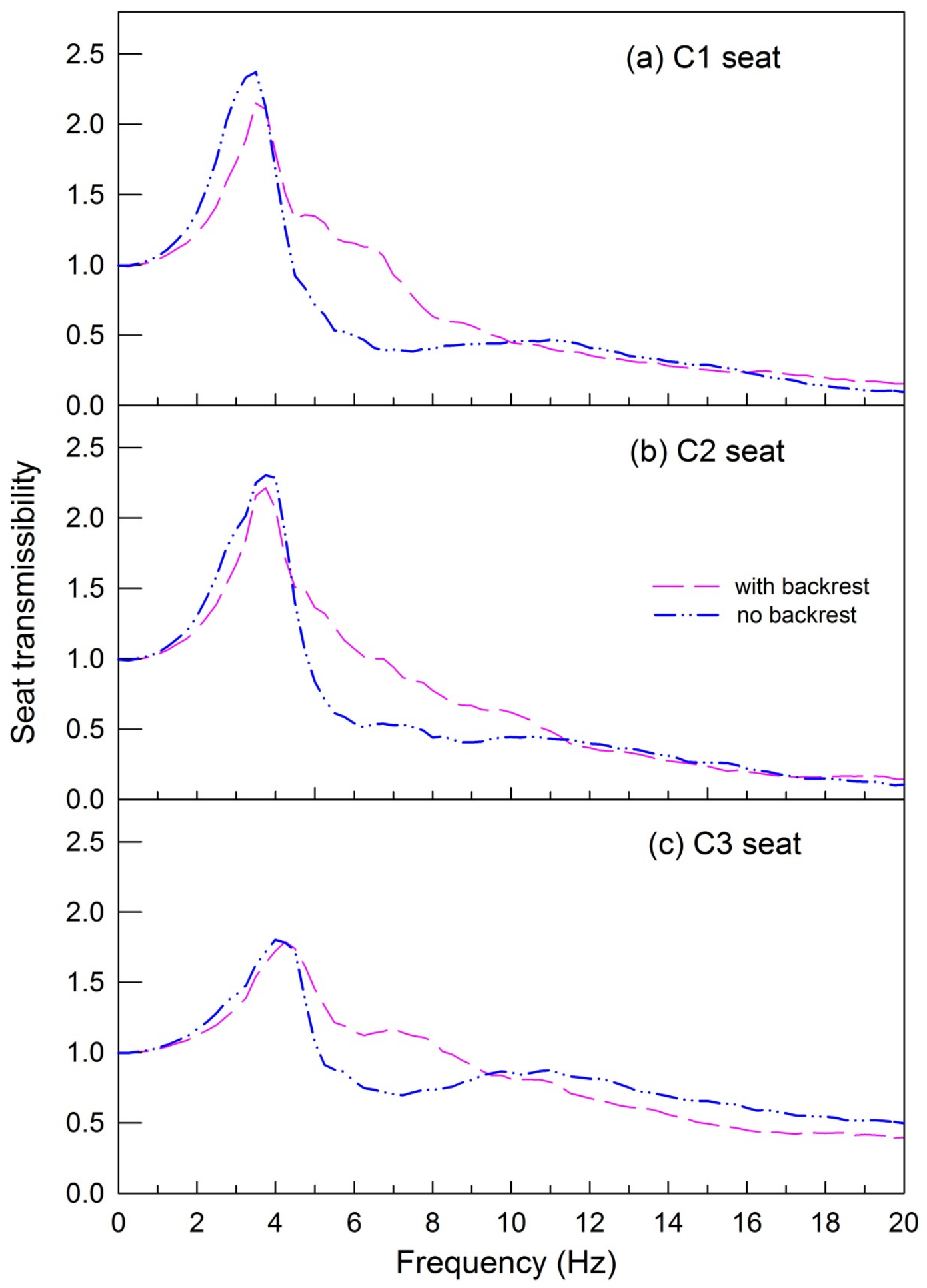


The application of SEAT values for predicting how compliant seats with backrests influence vibration discomfort Basri, B. \& Griffin, M. J. Nov 2014 In : Applied Ergonomics. 45, 6, p. 1461-1474 14 p.

\section{FIGURE 9}

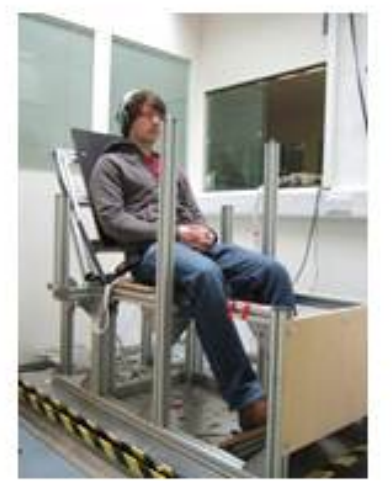

Rigid seat

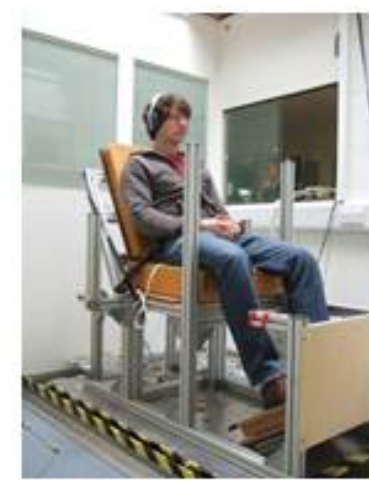

Compliant seat

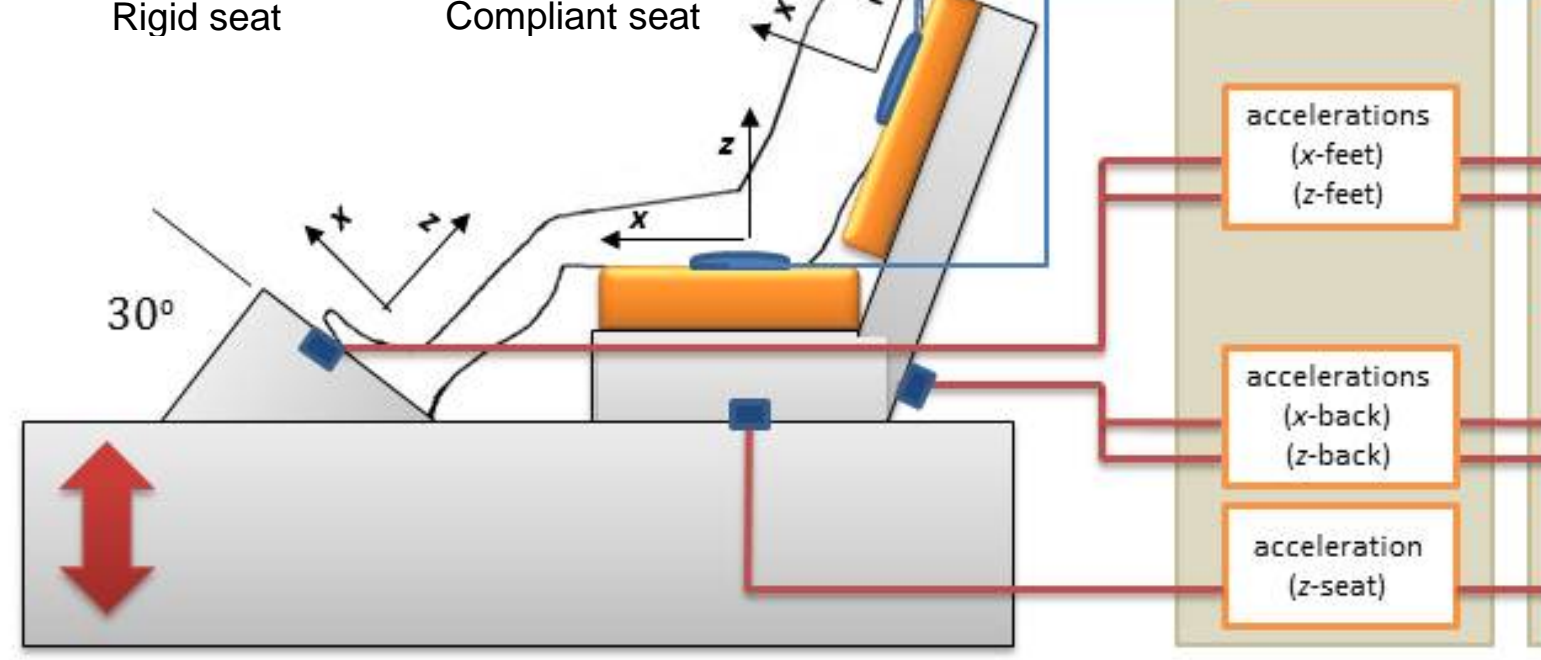

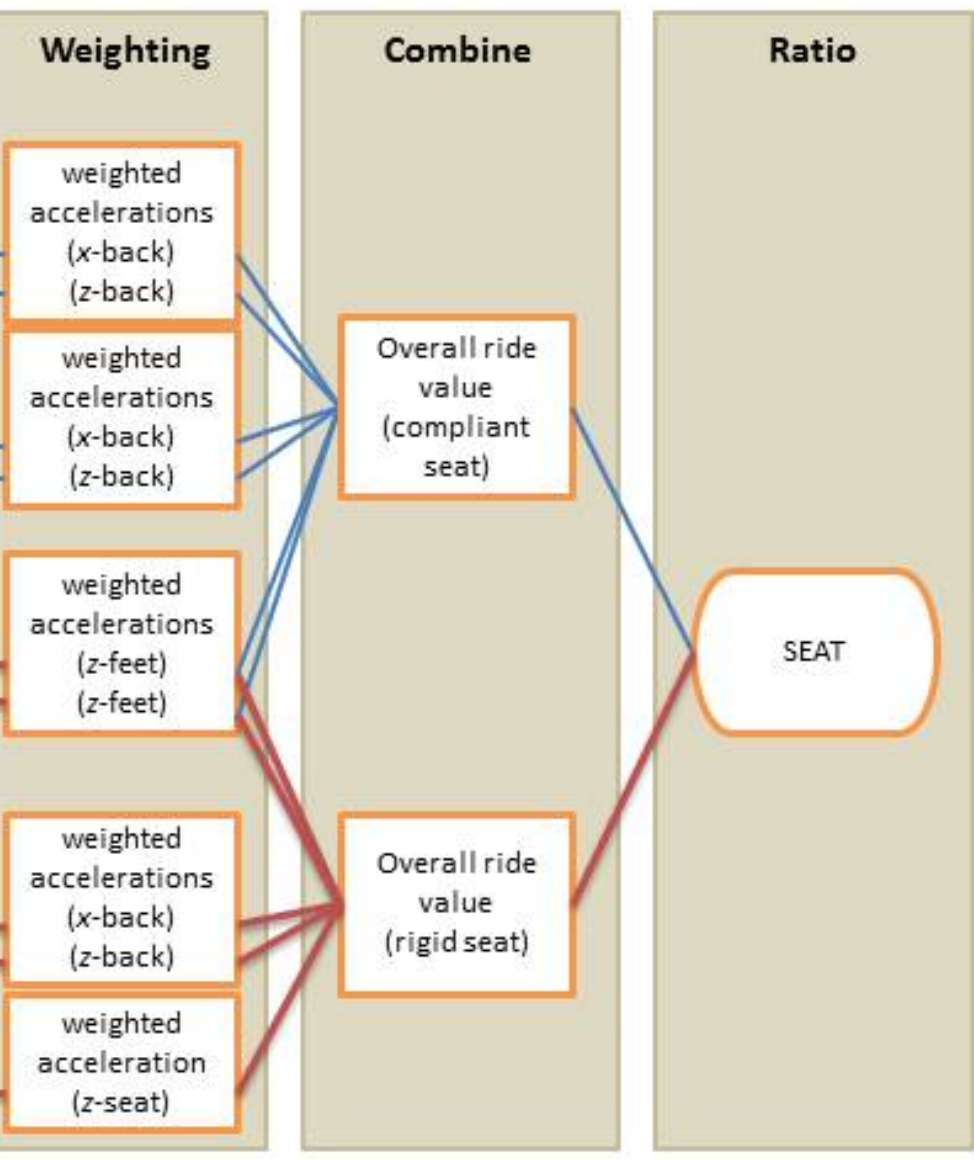


FIGURE 10

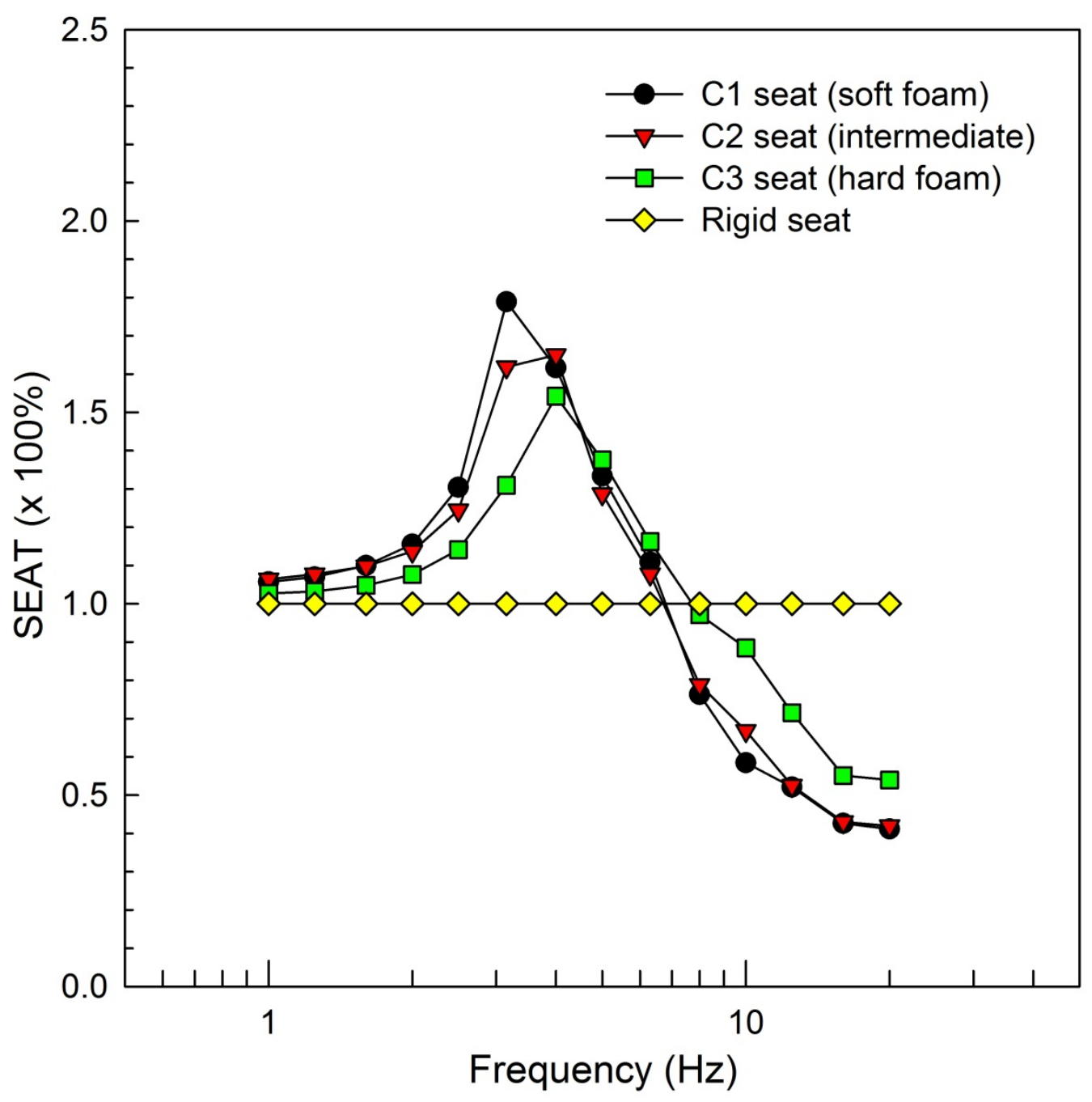


FIGURE 11

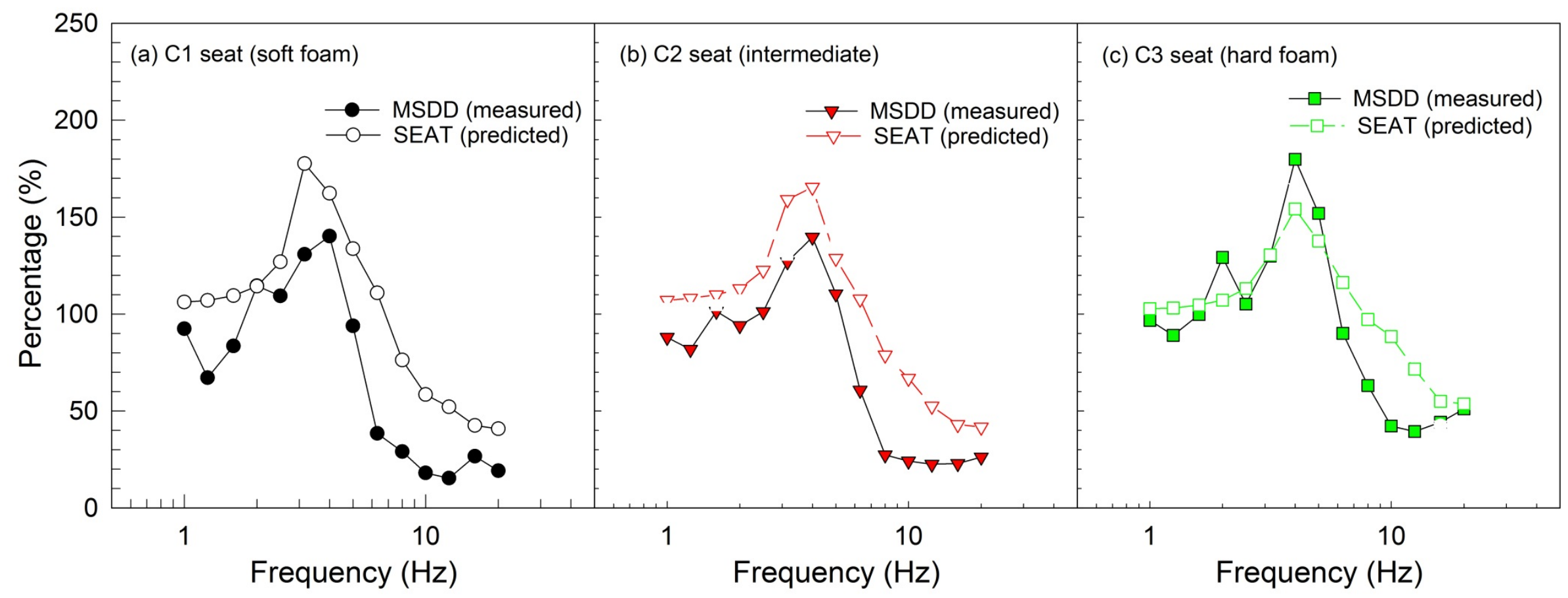



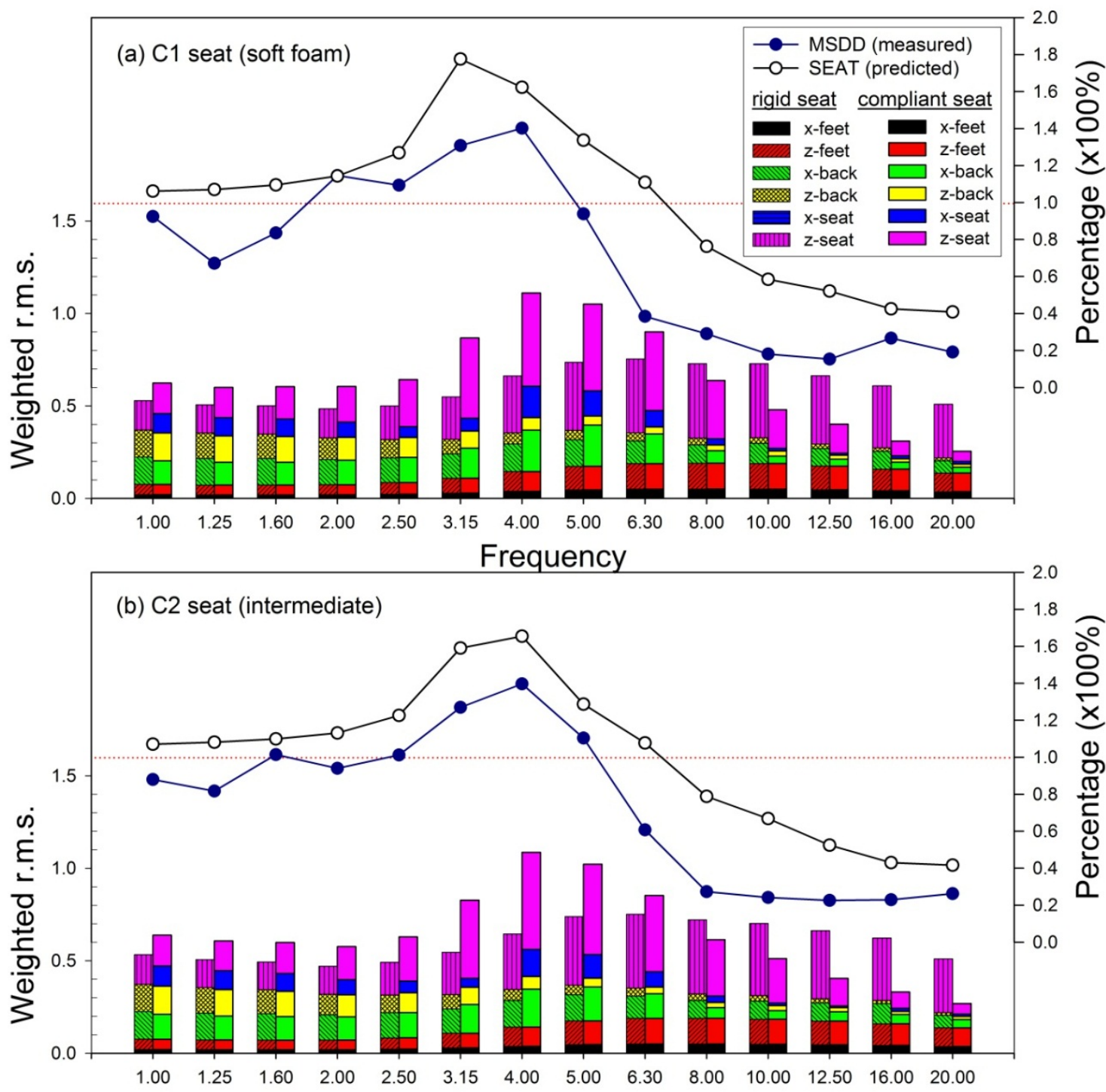

Frequency

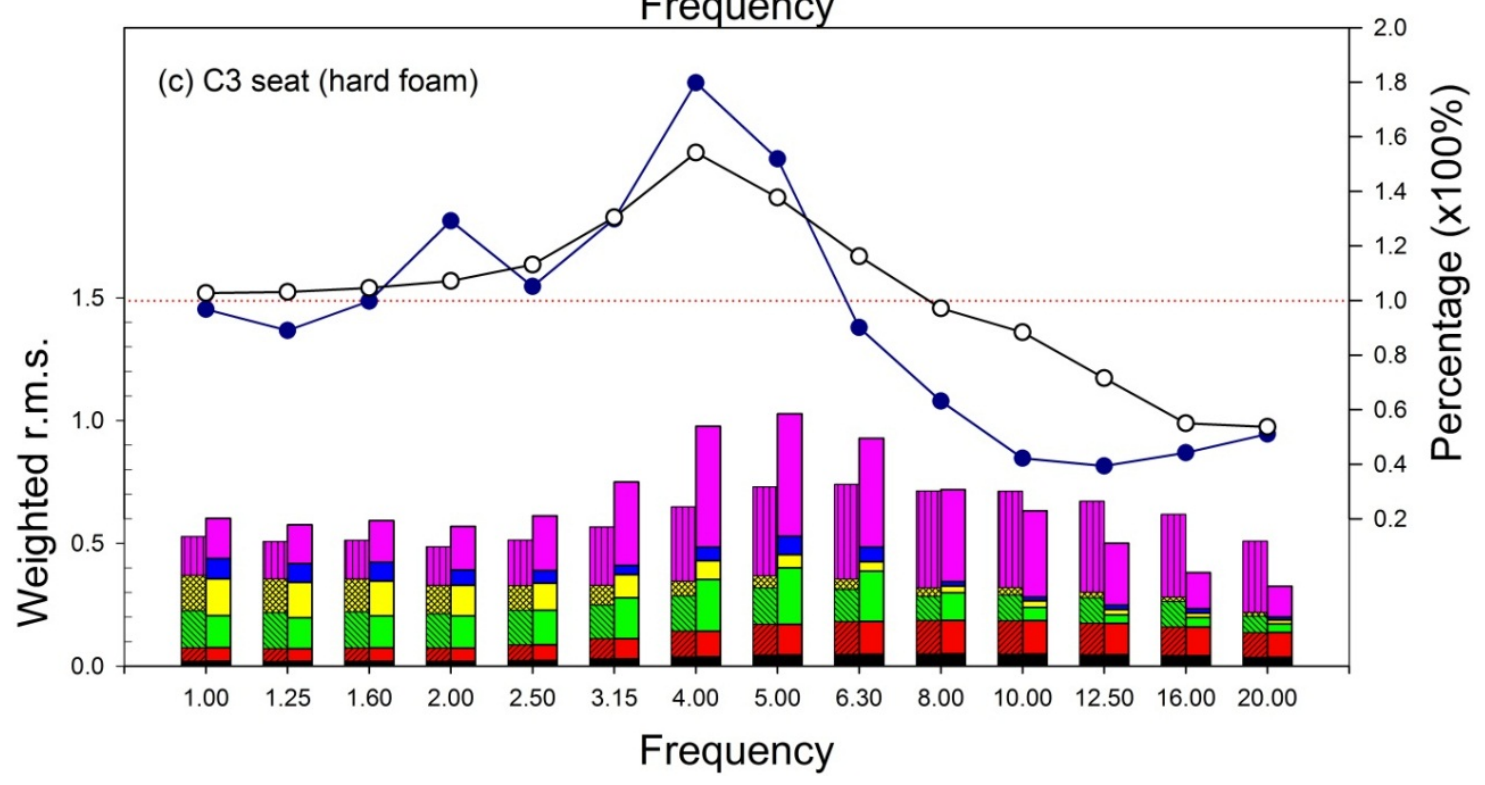


The application of SEAT values for predicting how compliant seats with backrests influence vibration discomfort Basri, B. \& Griffin, M. J. Nov 2014 In : Applied Ergonomics. 45, 6, p. 1461-1474 14 p.

TABLE 1

\begin{tabular}{|c|c|c|c|c|c|c|c|c|}
\hline \multirow[t]{2}{*}{ Frequency } & \multicolumn{4}{|c|}{ Exponent, $n$} & \multicolumn{4}{|c|}{ Constant, $k$} \\
\hline & $\mathrm{C} 01$ & $\mathrm{CO2}$ & $\mathrm{CO3}$ & $\mathrm{CO4}$ & $\mathrm{C} 01$ & $\mathrm{CO} 2$ & $\mathrm{CO3}$ & $\mathrm{CO4}$ \\
\hline 1.0 & 1.14 & 1.04 & 1.34 & 1.15 & 92.64 & 100.08 & 86.73 & 78.85 \\
\hline 1.25 & 1.06 & 0.97 & 1.05 & 1.27 & 92.86 & 94.31 & 96.03 & 82.44 \\
\hline 1.6 & 0.91 & 0.84 & 0.91 & 1.05 & 112.35 & 114.54 & 93.30 & 71.88 \\
\hline 2.0 & 0.92 & 0.91 & 0.87 & 0.94 & 126.87 & 121.93 & 113.36 & 80.45 \\
\hline 2.5 & 0.85 & 0.81 & 0.90 & 1.18 & 171.28 & 137.14 & 113.48 & 90.80 \\
\hline 3.15 & 0.89 & 0.73 & 1.06 & 0.93 & 199.86 & 187.66 & 150.64 & 100.21 \\
\hline 4 & 0.47 & 0.50 & 0.62 & 1.09 & 191.78 & 179.16 & 174.83 & 126.28 \\
\hline 5 & 0.44 & 0.48 & 0.50 & 0.69 & 180.87 & 175.46 & 176.02 & 154.96 \\
\hline 6.3 & 0.47 & 0.48 & 0.54 & 0.73 & 187.88 & 159.88 & 142.56 & 163.94 \\
\hline 8 & 0.44 & 0.37 & 0.59 & 0.48 & 142.89 & 132.48 & 144.51 & 157.10 \\
\hline 10 & 0.53 & 0.55 & 0.68 & 0.56 & 114.45 & 134.37 & 138.68 & 162.04 \\
\hline 12.5 & 0.78 & 0.67 & 0.70 & 0.52 & 110.22 & 112.10 & 133.33 & 159.72 \\
\hline 16 & 0.86 & 0.66 & 0.76 & 0.75 & 97.63 & 86.45 & 121.36 & 168.09 \\
\hline 20 & 0.82 & 0.80 & 0.85 & 0.83 & 88.22 & 102.23 & 115.86 & 157.14 \\
\hline
\end{tabular}


The application of SEAT values for predicting how compliant seats with backrests influence vibration discomfort Basri, B. \& Griffin, M. J. Nov 2014 In : Applied Ergonomics. 45, 6, p. 1461-1474 14 p.

TABLE 2

\begin{tabular}{|c|c|c|c|c|}
\hline \multirow[t]{2}{*}{ Seating condition } & \multicolumn{2}{|c|}{$\begin{array}{c}\text { Primary resonance frequency } \\
(\mathrm{Hz})\end{array}$} & \multicolumn{2}{|c|}{ Transmissibility at resonance } \\
\hline & No backrest & With backrest & No backrest & With backrest \\
\hline \multicolumn{5}{|l|}{ Floor to seat } \\
\hline C01 & 3.50 & 3.50 & 2.37 & 2.15 \\
\hline C02 & 3.75 & 3.75 & 2.30 & 2.21 \\
\hline $\mathrm{C} 03$ & 4.00 & 4.25 & 1.80 & 1.79 \\
\hline \multicolumn{5}{|l|}{ Floor to $x$-back } \\
\hline C01 & - & 4.00 & - & 1.51 \\
\hline C02 & - & 4.50 & - & 1.62 \\
\hline $\mathrm{C03}$ & - & 4.50 & - & 1.67 \\
\hline \multicolumn{5}{|l|}{ Floor to $z$-back } \\
\hline C01 & - & 3.50 & - & 1.23 \\
\hline $\mathrm{C} 02$ & - & 3.50 & - & 1.25 \\
\hline C03 & - & 4.25 & - & 1.28 \\
\hline
\end{tabular}


The application of SEAT values for predicting how compliant seats with backrests influence vibration discomfort Basri, B. \& Griffin, M. J. Nov 2014 In : Applied Ergonomics. 45, 6, p. 1461-1474 14 p.

TABLE 3

\begin{tabular}{lccc}
\hline Location & Axis & Weighting & Multiplying factor \\
\hline Seat & $x$ & $W_{\mathrm{d}}$ & 1.0 \\
& $Y$ & $W_{\mathrm{d}}$ & 1.0 \\
\hline Back & $z$ & $W_{\mathrm{b}}$ & 1.0 \\
\hline Feet & $x$ & $W_{\mathrm{c}}$ & 0.8 \\
& $Y$ & $W_{\mathrm{d}}$ & 0.5 \\
& $z$ & $W_{\mathrm{d}}$ & 0.4 \\
\hline & $x$ & $W_{\mathrm{b}}$ & 0.25 \\
& $Y$ & $W_{\mathrm{b}}$ & 0.25 \\
& & $W_{\mathrm{b}}$ & 0.4 \\
\hline
\end{tabular}

